\title{
Long-Term Climate Commitments Projected with Climate-Carbon Cycle Models
}

\author{
G.-K. Plattner, ${ }^{\mathrm{a}, \mathrm{n}}$ R. Knutti,${ }^{\mathrm{b}}$ F. Joos,${ }^{\mathrm{a}}$ T. F. Stocker, ${ }^{\mathrm{a}}$ W. von Bloh, ${ }^{\mathrm{c}}$ V. Brovkin, ${ }^{\mathrm{c}}$ \\ D. Cameron, ${ }^{\text {d }}$ E. Driesschaert,${ }^{\mathrm{e}}$ S. DutKiewicz, ${ }^{\mathrm{f}}$ M. Eby, ${ }^{\mathrm{g}}$ N. R. Edwards, ${ }^{\mathrm{h}}$ T. Fichefet, \\ J. C. Hargreaves, ${ }^{i}$ C. D. Jones,${ }^{j}$ M. F. Loutre, ${ }^{\mathrm{e}}$ H. D. Matthews, ${ }^{\mathrm{k}}$ A. Mouchet ${ }^{1}$ S. A. Müller,${ }^{\mathrm{a}}$ \\ S. Nawrath, ${ }^{\mathrm{c}}$ A. Price, ${ }^{\mathrm{m}}$ A. Sokolov,${ }^{\mathrm{f}}$ K. M. Strassmann, ${ }^{\mathrm{a}}$ AND A. J. Weaver ${ }^{\mathrm{g}}$ \\ ${ }^{a}$ Climate and Environmental Physics, Physics Institute, University of Bern, Bern, Switzerland \\ ${ }^{\mathrm{b}}$ IAC, ETH Zürich, Zürich, Switzerland \\ ${ }^{\mathrm{c}}$ Potsdam Institute for Climate Impact Research, Potsdam, Germany \\ ${ }^{\mathrm{d}}$ Edinburgh Bush Estate, Penicuik, Midlothian, United Kingdom \\ e Université Catholique de Louvain, Louvain-La-Neuve, Belgium \\ ${ }^{\mathrm{f}}$ Massachusetts Institute of Technology, Cambridge, Massachusetts \\ ${ }^{\mathrm{g}}$ School of Earth and Ocean Sciences, University of Victoria, Victoria, British Columbia, Canada \\ ${ }^{\mathrm{h}}$ The Open University, Milton Keynes, United Kingdom \\ ${ }^{\text {i }}$ Frontier Research Centre for Global Change, Yokohama, Kanagawa, Japan \\ ${ }^{\mathrm{j}}$ Met Office, Hadley Centre, Exeter, United Kingdom \\ ${ }^{\mathrm{k}}$ Geography, Planning and Environment, Concordia University, Montreal, Quebec, Canada \\ ${ }^{1}$ Astrophysics and Geophysics Institute, University of Liège, Liège, Belgium \\ ${ }^{\mathrm{m}}$ Southampton Regional e-Science Centre, University of Southampton, Southampton, United Kingdom
}

(Manuscript received 21 February 2007, in final form 1 October 2007)

\begin{abstract}
Eight earth system models of intermediate complexity (EMICs) are used to project climate change commitments for the recent Intergovernmental Panel on Climate Change's (IPCC's) Fourth Assessment Report (AR4). Simulations are run until the year 3000 A.D. and extend substantially farther into the future than conceptually similar simulations with atmosphere-ocean general circulation models (AOGCMs) coupled to carbon cycle models. In this paper the following are investigated: 1) the climate change commitment in response to stabilized greenhouse gases and stabilized total radiative forcing, 2) the climate change commitment in response to earlier $\mathrm{CO}_{2}$ emissions, and 3) emission trajectories for profiles leading to the stabilization of atmospheric $\mathrm{CO}_{2}$ and their uncertainties due to carbon cycle processes. Results over the twenty-first century compare reasonably well with results from AOGCMs, and the suite of EMICs proves well suited to complement more complex models. Substantial climate change commitments for sea level rise and global mean surface temperature increase after a stabilization of atmospheric greenhouse gases and radiative forcing in the year 2100 are identified. The additional warming by the year 3000 is $0.6-1.6 \mathrm{~K}$ for the low- $\mathrm{CO}_{2}$ IPCC Special Report on Emissions Scenarios (SRES) B1 scenario and 1.3-2.2 $\mathrm{K}$ for the high- $\mathrm{CO}_{2}$ SRES A2 scenario. Correspondingly, the post-2100 thermal expansion commitment is $0.3-1.1 \mathrm{~m}$ for SRES B1 and 0.5-2.2 $\mathrm{m}$ for SRES A2. Sea level continues to rise due to thermal expansion for several centuries after $\mathrm{CO}_{2}$ stabilization. In contrast, surface temperature changes slow down after a century. The meridional overturning circulation is weakened in all EMICs, but recovers to nearly initial values in all but one of the models after centuries for the scenarios considered. Emissions during the twenty-first century continue to impact atmospheric $\mathrm{CO}_{2}$ and climate even at year 3000. All models find that most of the anthropogenic carbon emissions are eventually taken up by the ocean $(49 \%-62 \%)$ in year 3000 , and that a substantial fraction $(15 \%-28 \%)$ is still airborne even $900 \mathrm{yr}$ after carbon emissions have ceased. Future stabilization of atmospheric $\mathrm{CO}_{2}$ and climate change requires a substantial reduction of $\mathrm{CO}_{2}$ emissions below present levels in all EMICs. This reduction needs to be substantially larger if carbon cycle-climate feedbacks are accounted for or if terrestrial $\mathrm{CO}_{2}$ fertilization is not operating. Large differences among EMICs are identified in both the response to increasing atmospheric $\mathrm{CO}_{2}$ and the response to climate change. This highlights the need for improved representations of carbon cycle processes in these models apart from the sensitivity to climate change. Sensitivity simulations with one single EMIC indicate that both carbon cycle and climate sensitivity related uncertainties on projected allowable emissions are substantial.
\end{abstract}

\footnotetext{
${ }^{\mathrm{n}}$ Current affiliation: IBP, ETH Zürich, Zürich, Switzerland.
}

Corresponding author address: Gian-Kasper Plattner, Institute of Biogeochemistry and Pollutant Dynamics, ETH Zürich, Universitätstr. 16, CH-8092 Zürich, Switzerland. E-mail: gian-kasper.plattner@env.ethz.ch 


\section{Introduction}

Model projections of future climate change are key to understanding and quantifying the impact of the anthropogenic perturbation on the climate system. Climate models are the only available tools for estimating the future climate response to specified perturbations and, thus, provide important information needed by policymakers and society. Proposed methods for mitigation or adaptation to climate change will be judged based partly on results from climate models.

With the most comprehensive atmosphere-ocean general circulation models (AOGCMs), some of them coupled to models of the global carbon cycle, it is currently feasible to project climate up to two centuries or so into the future (e.g., Meehl et al. 2005a; Hansen et al. 2007). Longer-term integrations are hindered mainly by computational limitations, and the same applies for multimember ensembles with AOGCMs. Earth system models of intermediate complexity (EMICs) on the other hand can help to substantially extend the climate projection time frame farther into the future. EMICs are usually dynamically simpler than comprehensive AOGCMs, although they might well be more complete in terms of climate system components that are included. Typically, EMICs are some composite of simplified versions of atmospheric and ocean model components, and a suite of parameterizations, sometimes even including representations of terrestrial and oceanic biogeochemical cycles. These less computationally expensive models (compared to AOGCMs) can be used to run simulations over thousands of years, to generate large simulation ensembles (Hargreaves et al. 2004), and to perform extensive sensitivity studies (e.g., Knutti et al. 2005) not possible with comprehensive AOGCMs. Computational efficiency in EMICs is however often paid for by a combination of lower spatial and/or temporal resolution, a reduction in explicitly modeled processes, and thus a need for more, sometimes simplified, parameterizations. Despite these limitations, EMICs have generally proven to be well suited to complement AOGCMs and their use has been growing over the last few years (Claussen et al. 2002).

In the framework of the recent Intergovernmental Panel on Climate Change's (IPCC's) Fourth Assessment Report (AR4; Solomon et al. 2007), a group of eight EMICs contributed to a project aiming at the investigation of long-term future climate change projections and commitments (Wigley 2005; Meehl et al. 2005b) until year 3000 A.D., thereby extending substantially farther into the future than the conceptually similar simulations with global coupled AOGCM-carbon cycle models (Meehl et al. 2007). Major goals were (i) to provide a comparison of globally averaged climate change projections over the next century from EMICs to available AOGCM projections, focusing on global mean temperature change, sea level rise, ocean heat uptake, and Atlantic meridional overturning; (ii) to quantify the long-term climate change commitment in response to stabilized greenhouse gases and stabilized total radiative forcing; (iii) to estimate the long-term climate change commitment in response to earlier $\mathrm{CO}_{2}$ emissions; and (iv) to monitor emission trajectories for profiles leading to stabilization of atmospheric $\mathrm{CO}_{2}$ and their uncertainties due to carbon cycle processes. Modeling results are presented and discussed along these major research themes. Overall, this modeling activity allows us to assess the range of uncertainty in climate projections across the entire model hierarchy. Previous studies investigating climate change and/or emission commitments either used AOGCMs (e.g., Meehl et al. 2005b; Tsutsui et al. 2007; Hansen et al. 2007), complex earth system models (Mikolajewicz et al. 2007; Lenton et al. 2006), or simple climate models (e.g., Wigley 2005; Friedlingstein and Solomon 2005).

The paper is structured as follows. In section 2, we briefly introduce the contributing EMICs, describe the experimental setups, and introduce the model metrics used to analyze and compare the model results. The section ends with a general overview of the uncertainties in the representation of the carbon cycle in these EMICs. In section 3, results from EMICs are presented, discussed, and compared to those of AOGCMs. We start with an evaluation of EMICs' standard physical model metrics against AOGCMs. In section 3a, globally averaged climate change projections over the next century are compared, the EMICs responses to stabilization of greenhouse gases and total radiative forcing are evaluated, and the long-term climate change commitment is quantified. In section $3 b$, the long-term climate change commitment in response to earlier $\mathrm{CO}_{2}$ emissions, the so-called zero-emissions commitment, is analyzed with those EMICs that include an interactive representation of the global carbon cycle. In section 3c, we then turn to emission trajectories for profiles leading to the stabilization of atmospheric $\mathrm{CO}_{2}$ and to the uncertainties due to carbon cycle processes and climate sensitivity using the same subgroup of EMICs and additional sensitivity simulations with a single EMIC, the Bern2.5CC EMIC. Finally, in section 3d, we study EMIC sensitivities to $\mathrm{CO}_{2}$ and climate and compare results to the Coupled Carbon Cycle-Climate Model Intercomparison Project study (C4MIP; Friedlingstein et al. 2006). Conclusions follow in section 4. 


\section{Models and methods}

\section{a. Models}

Results from eight EMICs, provided by seven modeling groups, are included in this study. The models are the University of Bern two-dimensional Carbon Cycle Climate Model (Bern2.5CC), the Coupled Global Ocean-Linear Drag Salt and Temperature Equation Integrator (C-GOLDSTEIN), versions 2 and $3 \alpha$ of the Climate and Biosphere Model (CLIMBER-2, CLIMBER-3 $\alpha$ ), the Liège Ocean Carbon Heteronomous model (LOCH)-Vegetation Continuous Description model (VECODE)-ECBilt-Coupled Large-Scale Ice-Ocean model (CLIO)-Antarctic and Greenland Ice Sheet Model (AGISM) ensemble (LOVECLIM), version 2.3 of the Massachusetts Institute of Technology's Integrated Global System Model (MIT-IGSM2.3), the Louvain-La-Neuve two-dimensional climate model (MoBidiC), and version 2.7 of the University of Victoria Earth System Climate Model (UVic 2.7). The main model characteristics are briefly described in appendix A and included in Randall et al. (2007). All contributing EMICs are simplified models compared to AOGCMs and are in general highly parameterized. Yet, the model structures and setups of individual EMICs are still very heterogeneous, ranging from zonally averaged ocean models coupled to energy balance models (Stocker et al. 1992), or coupled to statisticaldynamical models of the atmosphere (Petoukhov et al. 2000), to low-resolution three-dimensional ocean models, coupled to energy balance or simple dynamical models of the atmosphere (Opsteegh et al. 1998; Edwards and Marsh 2005). Some EMICs include a radiation code and prescribe greenhouse gases, while others use simplified equations to project radiative forcing from projected concentrations and abundances (Joos et al. 2001; Prather et al. 2001). Five out of the eight EMICs (Bern2.5CC, CLIMBER-2, LOVECLIM, MITIGSM2.3, and UVic 2.7) include interactive representations of the global carbon cycle, yet none of these models accounts for ocean-sediment interactions. Although carbon cycle processes in these EMICs are similarly simplified, global-scale quantities are generally in good agreement with more complex models. EMIC projections are compared to results from more complex AOGCMs from the Coupled Model Intercomparison Project [CMIP; Meehl et al. (2005a); information online at http://www-pcmdi.llnl.gov/] and to the models used in the C4MIP project, including four intermediate complexity models and seven coupled AOGCMs [Friedlingstein et al. (2006); information online at http:/ /www.c4mip.cnrs-gif.fr/background.html/]. Carbon cycle results from the Hadley Simple Climate Model
(Hadley-SCM; Jones et al. 2006a) have also been included in the EMIC comparison.

\section{b. Scenarios}

A set of well-defined emission scenarios, $\mathrm{CO}_{2}$ stabilization profiles, and emission pathways has been put together to ensure the comparability of different EMICs. Modeling groups were asked to provide results for different versions of their EMICs if available (e.g., with different ocean mixing parameterizations, or different atmospheric parameter settings) in order to assess the robustness of results with respect to different model parameterizations. In addition, as some EMICs allow for the equilibrium climate sensitivity to be tuned, the dependence of results on climate sensitivity ranging from 1.5 to $4.5 \mathrm{~K}$, the range given in the IPCC's Third Assessment Report (TAR; Houghton et al. 2001), could be estimated. While lower/higher climate sensitivity values can still not be ruled out completely (e.g., Knutti et al. 2006; Tomassini et al. 2007), the improved assessment provided in IPCC AR4 leaves the likely range more or less unchanged at $2.0-4.5 \mathrm{~K}$ (Meehl et al. 2007). The invitation letter to the EMIC community, the simulations protocols, and input files are available online (http://www.climate.unibe.ch/ emicAR4/index.html).

In a first set of simulations, atmospheric $\mathrm{CO}_{2}$ and total radiative forcing from $\mathrm{CO}_{2}$, non- $\mathrm{CO}_{2}$ greenhouse gases, and aerosols are projected from three of the six Special Report on Emissions Scenarios (SRES) illustrative emission scenarios until 2100 (Nakićenović et al. 2000) and kept at the year 2100 value afterward to investigate the climate change commitment in response to stabilized greenhouse gas concentrations and radiative forcing (Fig. 1). We emphasize that aerosol forcing, like all other radiative forcings, is kept constant after year 2100 , thereby neglecting a potential reduction in the (negative) aerosol radiative forcing by emission reduction toward $\mathrm{CO}_{2}$ stabilization. For the SRES scenarios $\mathrm{B} 1, \mathrm{~A} 1 \mathrm{~B}$, and $\mathrm{A} 2$, modeling groups either directly prescribed total radiative forcing or $\mathrm{CO}_{2}$ equivalents for the sum of $\mathrm{CO}_{2}$, non- $\mathrm{CO}_{2}$ greenhouse gases, and aerosols after year 2000 according to the BernCC (Joos et al. 2001) as published in appendix 2 of IPCC TAR (Houghton et al. 2001), or used their own set of emission/concentration inputs and calculated radiative forcing interactively from year 2000 to year 3000 . Those models without radiation code were asked to calculate radiative forcing from changes in $\mathrm{CO}_{2}$ or $\mathrm{CO}_{2}$ equivalents after IPCC TAR (Houghton et al. 2001) as

$$
\mathrm{RF}_{\mathrm{CO}_{2}}=5.35 \mathrm{~W} \mathrm{~m}{ }^{-2} \times \ln \left[\mathrm{CO}_{2}(t) / \mathrm{CO}_{2}\left(t_{0}\right)\right],
$$

where $\mathrm{CO}_{2}\left(t_{0}\right)$ is the atmospheric $\mathrm{CO}_{2}$ concentration at 


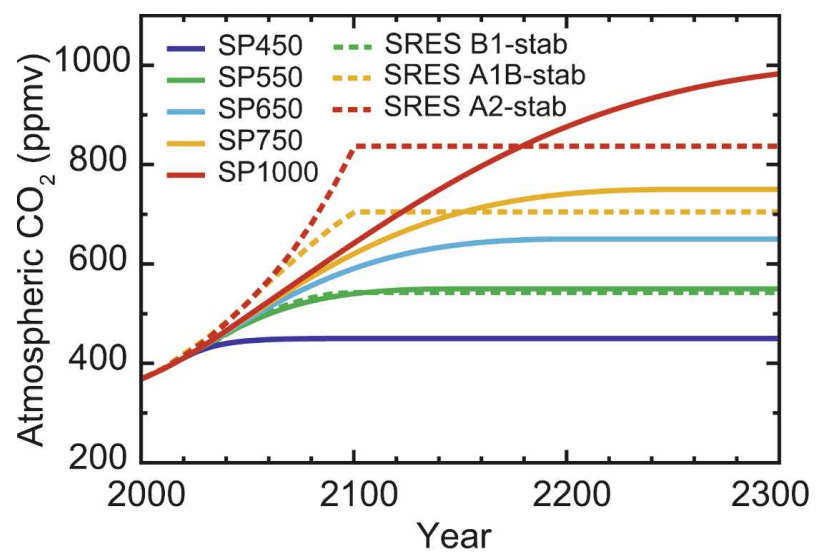

FIG. 1. Evolution of atmospheric $\mathrm{CO}_{2}$ for the $\mathrm{CO}_{2}$ stabilization pathways SP450-SP1000 and for three of the six illustrative SRES emission scenarios until the year 2100 with constant concentration thereafter. Atmospheric $\mathrm{CO}_{2}$ for SRES scenarios B1, A1B, and A2 until the year 2100 were taken from the BernCC model as published in appendix 2 of IPCC TAR (Houghton et al. 2001) and kept at the year 2100 value thereafter. A detailed technical description of the SP stabilization profiles can be found in appendix B.

preindustrial times, here $280 \mathrm{ppm}$ and year 1765 . No instructions were given on how to represent the historic period up to year 2000. These different approaches led to differences in projected total radiative forcings for individual EMICs. Forcing differences need to be kept in mind for one-to-one comparisons. In CMIP, AOGCM modeling groups were also allowed to use their own set of forcing components and calculate radiative forcing interactively (Meehl et al. 2005a) and not all AOGCMs included all of the relevant forcings (e.g., Santer et al. 2006).

In a second set of simulations, a series of prescribed $\mathrm{CO}_{2}$-only stabilization pathways have been applied to investigate climate change commitment in response to stabilized greenhouse gas concentrations and to investigate allowable $\mathrm{CO}_{2}$ emissions and carbon cycle-climate feedbacks. The atmospheric $\mathrm{CO}_{2}$ stabilization levels are 450, 550, 650, 750 and 1000 ppm (SP450-SP1000; Fig. 1). In addition, profiles aiming to study the impacts of a delayed stabilization at 450 and $550 \mathrm{ppm}$ (DSP450, DSP550) and of an overshoot of $\mathrm{CO}_{2}$ before stabilization at 350 and $450 \mathrm{ppm}$ (OSP350, OSP450) have been included. These stabilization profiles were constructed following Enting et al. (1994) and Wigley et al. (1996) using the most recent atmospheric $\mathrm{CO}_{2}$ observations, $\mathrm{CO}_{2}$ projections with the BernCC model (Joos et al. 2001) for the A1T emission scenario over the next few decades, and a Padé approximant (a ratio of two polynomials) (Enting et al. 1994) leading to stabilization. A more detailed technical description of these stabilization profiles can be found in appendix B.
In a third set of simulations, the climate change commitment in response to earlier emissions is investigated. These simulations were performed by five EMICs that include an interactive carbon cycle component to project atmospheric $\mathrm{CO}_{2}$ from carbon emissions. Anthropogenic carbon emissions for the suite of previously introduced SP450-SP1000 $\mathrm{CO}_{2}$ stabilization profiles have been inferred from simulations with the BernCC model and prescribed in the five EMICs until the year 2100. After the year 2100, anthropogenic carbon emissions were set to zero until the end of the simulation.

We restrict our analysis to globally averaged results. Given the reduced complexity of the EMICs, only results on continental to global scales should be interpreted (Stocker and Knutti 2003). In addition, so far, only a few other intercomparisons on EMIC climate change projections have been published (e.g., Petoukhov et al. 2005; Gregory et al. 2005), leaving room for further studies and, in particular, comparisons to AOGCM results.

\section{c. Model metrics}

\section{1) PHYSICAL}

EMIC outputs from idealized $\mathrm{CO}_{2}$-only stabilization profiles have been used to determine key model characteristics, such as equilibrium climate sensitivity (ECS, the increase in global mean surface temperature for a doubling of atmospheric $\mathrm{CO}_{2}$ concentration; $\mathrm{K}$ ), transient climate response (TCR, the increase in global mean surface temperature in a $1 \% \mathrm{yr}^{-1} \mathrm{CO}_{2}$ increase experiment at the time of $\mathrm{CO}_{2}$ doubling; $\mathrm{K}$ ), and ocean heat uptake efficiency [the ratio of the net downward top-of-the-atmosphere radiative flux-assumed equal to the ocean heat uptake on decadal time scales-to TCR at the time of $\mathrm{CO}_{2}$ doubling in a $1 \% \mathrm{yr}^{-1}$ increase experiment; $\mathrm{W} \mathrm{m}^{-2} \mathrm{~K}^{-1}$; Gregory and Mitchell (1997); Raper et al. (2002)]. Ocean heat uptake efficiency is a measure of the rate at which heat storage by the global ocean increases as the global average temperature rises. A larger atmospheric warming for a given forcing, associated with a smaller ocean heat uptake, reduces the global energy imbalance at the top of the atmosphere, resulting in a smaller value for the ocean heat uptake efficiency. These metrics describe the way a climate model responds to changes in the external forcing (Meehl et al. 2007) and are used to compare (i) different EMICs and (ii) the suite of EMICs with the IPCC AR4 AOGCMs (Meehl et al. 2007). All metrics have been determined from an idealized $2 \times \mathrm{CO}_{2}$ simulation, where $\mathrm{CO}_{2}$ increases from its preindustrial value by $1 \%$ $\mathrm{yr}^{-1}$ to the $2 \times \mathrm{CO}_{2}$ level at year 70 , and is then kept 
constant until model year 3000. Equilibrium climate sensitivity is then calculated as the change in global mean surface air temperature at year 3000, whereas TCR and ocean heat uptake efficiency are calculated from 20 -yr-averaged quantities centered at the time of $\mathrm{CO}_{2}$ doubling.

\section{2) CARbon CYCLE}

We analyze model sensitivities to increasing atmospheric $\mathrm{CO}_{2}$ and climate change. The analysis is inspired by Friedlingstein et al. (2006), but we use runs with prescribed $\mathrm{CO}_{2}$ instead of prescribed emissions. The land and ocean carbon sensitivity to increasing $\mathrm{CO}_{2}$ is determined from simulations where $\mathrm{CO}_{2}$ was prescribed as in the standard setup ("coupled"), but where $\mathrm{CO}_{2}$ did not affect climate ("uncoupled"). The land and ocean carbon sensitivity to climate change is directly determined from the difference between the coupled and the uncoupled simulations. This allows us to exactly separate the sensitivities to $\mathrm{CO}_{2}$ and climate because the atmospheric $\mathrm{CO}_{2}$ is identical in the two runs. We note that model sensitivities presented here are not directly comparable to the results presented by Friedlingstein et al. (2006) given the differences in the scenario and method of calculation between the two studies.

The overall sensitivities of land $\left(\Delta C_{L}^{\text {cou }}\right)$ and ocean $\left(\Delta C_{O}^{\text {cou }}\right)$ carbon uptake to an increase in atmospheric $\mathrm{CO}_{2}$ and climate change, expressed in terms of global mean surface air temperature change, can be written as

$$
\begin{aligned}
& \Delta C_{L}^{\text {cou }}=\beta_{L} \Delta C_{A}+\gamma_{L} \Delta T_{A}^{\text {cou }}, \\
& \Delta C_{O}^{\text {cou }}=\beta_{O} \Delta C_{A}+\gamma_{O} \Delta T_{A}^{\text {cou }},
\end{aligned}
$$

where $\Delta C_{L}^{\text {cou }}$ and $\Delta C_{O}^{\text {cou }}$ are the respective changes in global land and ocean carbon storage (in GtC), $\Delta C_{A}$ is the change in atmospheric $\mathrm{CO}_{2}$ (in ppm), and $\Delta T_{A}^{\text {cou }}$ is the change in global mean surface air temperature in the coupled simulation. Note that here " $\Delta$ " stands for a temporal change since preindustrial times; that is, for temperature, $\Delta T_{A}^{\mathrm{cou}}=\Delta T_{A}^{\mathrm{cou}}(t)-\Delta T_{A}^{\mathrm{cou}}\left(t_{0}\right)$. The land $\left(\beta_{L}\right)$ and ocean $\left(\beta_{O}\right)$ carbon sensitivity parameters to increasing $\mathrm{CO}_{2}$ can be determined from the uncoupled simulations as

$$
\begin{aligned}
& \beta_{L}=\Delta C_{L}^{\mathrm{unc}} / \Delta C_{A}, \\
& \beta_{O}=\Delta C_{O}^{\mathrm{cou}} / \Delta C_{A},
\end{aligned}
$$

where $\beta_{L}$ is roughly a measure of the models' $\mathrm{CO}_{2}$ fertilization and $\beta_{O}$ is a measure of the models' surface to deep ocean transport rate. Because $\Delta C_{A}$ is identical in the prescribed $\mathrm{CO}_{2}$ case, the land $\left(\gamma_{L}\right)$ and ocean $\left(\gamma_{O}\right)$ carbon sensitivity parameters to an increase in temperature can be directly determined from the dif- ference in carbon storage between the uncoupled and coupled simulations:

$$
\begin{aligned}
& \gamma_{L}=\left(\Delta C_{L}^{\text {cou }}-\Delta C_{L}^{\text {unc }}\right) / \Delta T_{A}^{\text {cou }}, \\
& \gamma_{O}=\left(\Delta C_{O}^{\text {cou }}-\Delta C_{O}^{\text {unc }}\right) / \Delta T_{A}^{\text {cou }},
\end{aligned}
$$

where $\gamma_{L}$ is a measure of the models' release/uptake of carbon in response to factors such as accelerated soil carbon and nitrogen overturning, forest dieback, and stimulated productivity under global warming; and $\gamma_{O}$ is a measure of the models' reduction in the rate of ocean carbon uptake under global warming in response to changes in $\mathrm{CO}_{2}$ solubility, surface to deep ocean transport, and the biological carbon cycle. The sensitivity of the global mean surface air temperature to changing atmospheric $\mathrm{CO}_{2}, \alpha$, is defined as

$$
\alpha=\Delta T_{A}^{\mathrm{cou}} / \Delta C_{A} .
$$

Here, $\alpha$ provides complementary information to the equilibrium climate sensitivity and TCR, and is useful for comparing our EMIC results to the C4MIP study (Friedlingstein et al. 2006; Denman et al. 2007).

Finally, the carbon cycle-climate feedback factor, $\xi$, is determined as the ratio between uncoupled and coupled cumulated emissions:

$$
\xi=\Delta C_{E}^{\mathrm{unc}} / \Delta C_{E}^{\mathrm{cou}},
$$

where $\Delta C_{E}^{\text {unc }}$ and $\Delta C_{E}^{\text {cou }}$ are the respective cumulated $\mathrm{CO}_{2}$ emissions in the uncoupled and coupled simulations (in GtC). We use $\xi$ to characterize the overall feedback to the climate change. The carbon cycleclimate feedback factor is greater than 1 if the climate change leads to reduced $\mathrm{CO}_{2}$ uptake by oceans and the terrestrial biosphere, and thus to lower allowable emissions for a given $\mathrm{CO}_{2}$ pathway or higher atmospheric $\mathrm{CO}_{2}$ concentrations for a given emission pathway (i.e., a positive carbon cycle-climate feedback). The factor is less than 1 for a negative carbon cycle-climate feedback. In contrast to our emission-based definition, Denman et al. (2007) determine the feedback factor from the ratio of coupled to uncoupled atmospheric $\mathrm{CO}_{2}$ concentrations.

\section{d. Uncertainties in the representation of the carbon cycle}

Uncertainties in the carbon uptake by land and ocean directly translate into uncertainties in projected atmospheric $\mathrm{CO}_{2}$ or allowable carbon emissions (Joos et al. 2001; Prentice et al. 2001; Edmonds et al. 2004; Jones et al. 2006a; Matthews 2006). For a comprehensive discussion of the governing processes, feedbacks, their uncertainties, and scales, see the reviews by Prentice et al. (2001), Field and Raupach (2004), and Denman et al. (2007). Uncertainties arise from the necessity to param- 
eterize processes covering the spatiotemporal scales of biochemical reactions in leaves, bacteria, and marine organisms to the decadal-to-century scales of soil carbon dynamics and ocean overturning to the millennial and global scales of the sediment and weathering cycles. Key uncertainties for decadal-to-century scale carbon fluxes are inter alia related to the rate of surface to deep ocean exchange of carbon and nutrients in the ocean and its change under global warming; to the response of terrestrial productivity (and water use efficiency) to changes in atmospheric $\mathrm{CO}_{2}$, climate, and the availability of nitrogen and other nutrients; to the rate of soil overturning and thawing of frozen soils under current and altered environmental conditions; to vegetation dynamics including forest dieback and establishment; and importantly to a wide range of human interferences with natural systems. Constraints on the continental-to-global scale ocean and land carbon fluxes arise from direct atmospheric observations of $\mathrm{CO}_{2}$, its isotopes, and $\mathrm{O}_{2}$; from the observed distributions of a wide range of tracers such as chlorofluorocarbons (CFCs), radiocarbon, nutrients, alkalinity, and carbon within the ocean; from measurements of carbon fluxes at the land-atmosphere and land-ocean interfaces; from soil radiocarbon measurements; from paleobotanical vegetation cover data; and from statistics on fossil, industrial, and land-use carbon emissions.

The feedbacks between the carbon cycle and the physical climate system are estimated to be positive both from palaeodata (Jansen et al. 2007; Joos and Prentice 2004) and our current system understanding (Friedlingstein et al. 2006; Greenblatt and Sarmiento 2004), very likely reducing the carbon uptake by ocean and land under warming relative to a steady climate (Sarmiento and Le Quéré 1996; Joos et al. 1999; Meyer et al. 1999; Cox et al. 2000; Friedlingstein et al. 2001; Joos et al. 2001; Prentice et al. 2001; Plattner et al. 2001; Matthews 2005; Jones et al. 2006b; Friedlingstein et al. 2006).

The ensemble of models used in this study covers the range compatible with the available data and the current system understanding, and reflects the controversy in the literature on a range of processes. The ensemble includes models with a very low terrestrial response to rising $\mathrm{CO}_{2}$ (" $\mathrm{CO}_{2}$ fertilization") such as the Terrestrial Ecosystem Model (TEM; embedded in MIT-IGSM2.3), which is strongly limited by nitrogen availability, to the Hadley-SCM that shows a very strong $\mathrm{CO}_{2}$ fertilization unconstrained by any nutrient limitation. Similarly, the Hadley-SCM displays a very large release of land carbon in response to global warming as it is calibrated to follow the full Hadley AOGCM (HadCM3LC), which has only a single soil carbon pool and strong sensitivity of vegetation to climate, whereas terrestrial carbon storage increases strongly under the VECODE model scheme (used in CLIMBER-2, LOVECLIM, and MoBidiC) and increases weakly in the TEM. The terrestrial models thus range from practically absent to very strong $\mathrm{CO}_{2}$ fertilization and from very strong carbon release in response to accelerated soil carbon overturning and forest dieback to additional carbon uptake under global warming as it might be driven by an accelerated nitrogen cycle. The models, however, do not account for land use and land-use changes (McGuire et al. 2001; Strassmann et al. 2008). Turning to the ocean, the CLIMBER-2 model, for example, features slow surface to deep ocean transport of anthropogenic carbon, whereas the Bern2.5CC shows a (too) vigorous transport. The models show a weak to moderate reduction in ocean carbon uptake under global warming as is expected from reduced solubility and increased stratification. Future changes in ocean biology are highly uncertain, yet many modeling studies using simple representations of ocean biology suggest that associated changes tend to partly offset the physically driven changes in ocean carbon uptake in these models (e.g., Plattner et al. 2001). Changes in ocean biology are not taken into account in the LOVECLIM, UVic 2.7, and HadleySCM models.

\section{Results and discussion}

As a first analysis, standard physical model metrics of the eight contributing EMICs and the Hadley-SCM are compared with those of AOGCMs. The equilibrium climate sensitivity, TCR, and ocean heat uptake efficiency of the EMICs compare reasonably well with the AOGCM results (Fig. 2; Table 1).

The equilibrium climate sensitivity ranges from 1.9 to $4.3 \mathrm{~K}$ for the suite of EMICs (AOGCMs: 2.1 to $4.4 \mathrm{~K}$ ), corresponding to the likely range of 2.0 to $4.5 \mathrm{~K}$ given in IPCC AR4 (Solomon et al. 2007). However, climate sensitivity is a somewhat tunable parameter in some EMICs. The TCR from EMICs ranges between 0.9 and $2.3 \mathrm{~K}$ (AOGCMs: 1.2 and $2.6 \mathrm{~K}$ ). Two out of the eight EMICs have climate sensitivities and TCR's lower than the set of AOGCMs. The sensitivities for these two models are also below the TCR range for the respective climate sensitivities determined from a large perturbed physics ensemble of the Bern2.5D EMIC (gray dots), exploring a wide range of ocean model parameter combinations (Knutti et al. 2005). The TCR and equilibrium climate sensitivity in EMICs and AOGCMs are clearly linked and the relationship is nonlinear (Wigley and Schlesinger 1985; Harvey 1986; Knutti et al. 2005). In general, TCR is higher at higher climate sensitivity for both EMICs and AOGCMs, but the relationship 

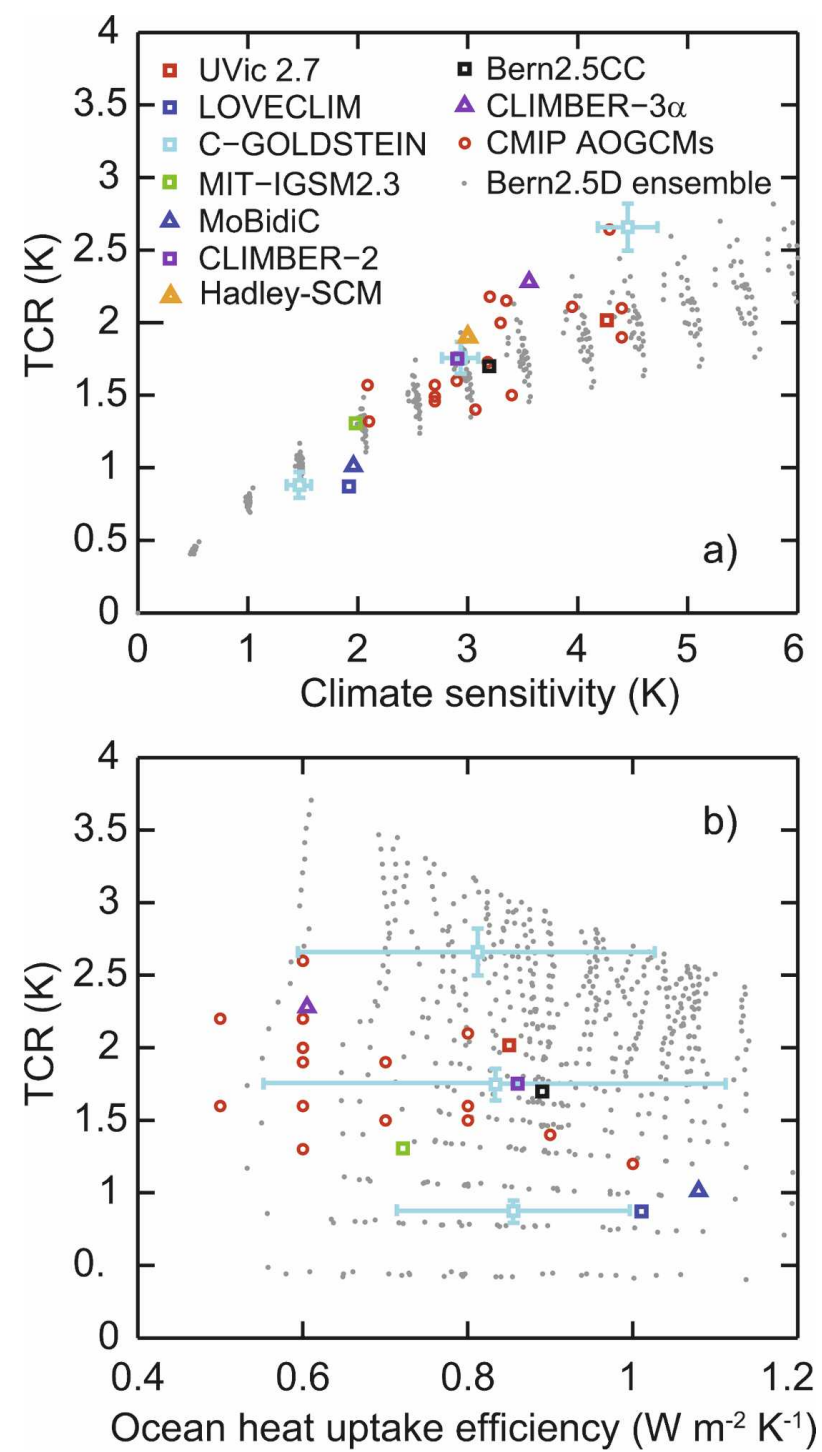

FIG. 2. TCR vs (a) equilibrium climate sensitivity (ECS) and (b) ocean heat uptake efficiency $(\kappa)$ for eight EMICs and the Hadley-SCM (colored squares and triangles), AOGCMs (red circles), and from a large ensemble of the Bern2.5D EMIC (Knutti et al. 2005) using different ocean vertical diffusivities and mixing parameterization (gray dots). For the C-GOLDSTEIN model, ensemble means and \pm 2 standard deviation uncertainties due to atmosphere, ocean, and sea ice parameter perturbations are given for three ensembles with climate sensitivities of 1.5, 3.0, and $4.5 \mathrm{~K}$. EMIC results are derived from an idealized $2 \times \mathrm{CO}_{2}$ profile with prescribed atmospheric $\mathrm{CO}_{2}$ (see main text and Table 1 for details).

becomes weaker at higher values of climate sensitivity and TCR.

Ocean heat uptake efficiency for the group of EMICs is between 0.6 and $1.1 \mathrm{~W} \mathrm{~m}^{-2} \mathrm{~K}^{-1}$ compared to 0.5 and 1.0 for AOGCMs. From Fig. $2 b$ it seems that there is only a weak relationship between TCR and ocean heat uptake efficiency, with a tendency toward lower TCR for higher values of ocean heat uptake efficiency. No clear relationship was found for climate sensitivity and ocean heat uptake efficiency, in contrast to the results from AOGCMs reported by Raper et al. (2002). Ocean heat uptake efficiencies from the large Bern2.5D ensemble do not extend as low as for two of the AOGCMs, indicating that there is an inherent lower limit for ocean heat uptake for this particular EMIC, probably related to numerical diffusion.

Overall, we find that the strength and rapidity of the surface temperature response to external forcing and the rate at which heat storage by the global ocean increases as the global average temperature rises are well represented in these EMICs. The generally close agreement between EMICs and AOGCMs supports the use of intermediate-complexity models to project climate change on the global scale and to complement more comprehensive AOGCMs.

\section{a. Constant atmospheric composition commitment}

Climate change commitment is addressed by keeping the greenhouse gas concentrations and total radiative forcing constant after the year 2100 (Fig. 3). The atmospheric composition and radiative forcing from $\mathrm{CO}_{2}$, non- $\mathrm{CO}_{2}$ greenhouse gases, and aerosols are projected from SRES emission scenarios A1B, A2, and B1 until 2100 (Nakićenović et al. 2000) and kept at the year 2100 value afterward (see Fig. 1). Prescribed atmospheric $\mathrm{CO}_{2}$ concentrations in year 2100 (and constant thereafter) from appendix 2 of IPCC TAR (Houghton et al. 2001; BernCC model) are 540 ppm in scenario B1, 703 $\mathrm{ppm}$ in $\mathrm{A} 1 \mathrm{~B}$, and $836 \mathrm{ppm}$ in $\mathrm{A} 2$. These three scenarios thus represent examples of low (B1), medium (A1B), and high (A2) increases in atmospheric $\mathrm{CO}_{2}$, the dominant anthropogenic greenhouse gas, and in the total radiative forcing among the suite of SRES scenarios. They have been chosen to illustrate the climate model response to a given emission pathway. They do not span the full range of economically and technologically feasible scenarios, and the selection of the three cases does not imply a higher likelihood or feasibility of these cases versus others.

All EMIC and AOGCM projections show that sea level continues to rise due to thermal expansion for several centuries after stabilizing the atmospheric $\mathrm{CO}_{2}$ concentrations and total radiative forcing. Thermal expansion for SRES A1B from EMICs by the year 2100 reaches $0.15-0.45 \mathrm{~m}$ and continues to increase substantially until the year 3000 reaching $0.6-2.0 \mathrm{~m}$ (Fig. 3). Note that none of these models includes the additional runoff from Greenland or other land-based ice sheets or glaciers. [Over the 1961-2003 period, thermal expan- 
TABLE 1. EMICs model parameters describing the response to changes in the external forcing. Model details for EMICs and Hadley-SCM can be found in appendix A; details on the AOGCM AR4 and C4MIP models are given in Meehl et al. (2005a) and Friedlingstein et al. (2006). For the C-GOLDSTEIN model, ensemble means from three perturbed physics ensembles with climate sensitivities 3.0 (standard), 1.5, and 4.5 K (in parenthesis) are given. Results from the Hadley-SCM are included in the EMIC mean and range. ECS, TCR, and ocean heat uptake efficiency ( $\kappa$; Gregory and Mitchell 1997; Raper et al. 2002) are defined as in Meehl et al. (2007). EMIC results are derived from an idealized $2 \times \mathrm{CO}_{2}$ profile with prescribed atmospheric $\mathrm{CO}_{2}$. ECS is calculated as the change in global mean surface air temperature at year 3000. TCR and $\kappa$ are calculated from 20 -yr-averaged quantities centered at the time of $\mathrm{CO}_{2}$ doubling (here year 70; see the text for details).

\begin{tabular}{|c|c|c|c|}
\hline Model & ECS (K) & $\operatorname{TCR}(\mathrm{K})$ & $\kappa\left(\mathrm{W} \mathrm{m}^{-2} \mathrm{~K}^{-1}\right)$ \\
\hline \multicolumn{4}{|c|}{ EMICs } \\
\hline Bern2.5CC & 3.20 & 1.70 & 0.89 \\
\hline C-GOLDSTEIN & $2.93(1.48-4.45)$ & $1.75(0.88-2.66)$ & $0.83(0.86-0.81)$ \\
\hline CLIMBER-2 & 2.91 & 1.75 & 0.86 \\
\hline CLIMBER-2-LPJ & 2.84 & 1.70 & 0.87 \\
\hline CLIMBER- $3 \alpha$ & 3.56 & 2.28 & 0.61 \\
\hline LOVECLIM & 1.92 & 0.87 & 1.01 \\
\hline MIT-IGSM2.3 & 1.98 & 1.31 & 0.72 \\
\hline MoBidiC & 1.96 & 1.01 & 1.08 \\
\hline UVic 2.7 & 4.27 & 2.02 & 0.85 \\
\hline Hadley-SCM & 3.00 & 1.90 & - \\
\hline EMIC mean & 2.86 & 1.63 & 0.86 \\
\hline EMIC range & $1.92-4.27$ & $0.87-2.28$ & $0.61-1.08$ \\
\hline \multicolumn{4}{|c|}{ AOGCMs AR4 } \\
\hline AOGCMs AR4 mean & 3.26 & 1.76 & 0.69 \\
\hline AOGCMs AR4 range & $2.1-4.4$ & $1.2-2.6$ & $0.5-1.0$ \\
\hline \multicolumn{4}{|c|}{ C4MIP models } \\
\hline C4MIP mean & - & 2.1 & - \\
\hline C4MIP range & - & $1.2-2.7$ & - \\
\hline
\end{tabular}

sion is estimated to contribute about $23 \%$ to the total observed global sea level rise (Bindoff et al. 2007).] In contrast, surface air temperature changes level off after approximately a century, reaching $1.3-3.5 \mathrm{~K}$ by the year 2100 relative to the year 2000 for SRES A1B, only modestly increasing thereafter to $2.2-4.6 \mathrm{~K}$ warming by year 3000 . The Atlantic meridional overturning circulation (MOC; here defined as the maximum, annual mean overturning in the North Atlantic below a depth of $500 \mathrm{~m}$ ) is temporarily weakened in all EMICs, but recovers to nearly initial values in all but one of the models after several centuries. The complete shutdown of the Atlantic MOC in the Bern2.5CC EMIC leads to an additional contribution to sea level rise as compared to the other EMICs, a finding discussed in detail by Knutti and Stocker (2000). It also illustrates that the MOC might be close to a threshold in some of the models, and that for strong enough forcings that last long enough, nonlinear responses in the climate system could be triggered (e.g., Stocker and Schmittner 1997; Stouffer and Manabe 1999; Hargreaves and Annan 2006; Mikolajewicz et al. 2007). In these kinds of models, the stability of the MOC depends quite strongly on the various model parameters, in particular, on how ocean mixing is parameterized (Knutti et al. 2000). Note also that some AOGCMs show strong downward drifts in the MOC already in the historical period (Schneider et al. 2007; Meehl et al. 2007). These are caused by a drift in the model control state and are unrelated to the forcing.

Projected surface warming and sea level rise from thermal expansion by years 2100,2300 , and 3000 for SRES scenarios B1, A1B, and A2 (with constant atmospheric composition after 2100; Fig. 1) and all EMICs are summarized in Fig. 4. The EMIC results cover a wide range for both surface warming and thermal expansion and this range increases over time. The global mean surface air temperature increase over the twentyfirst century ranges from 0.7 to $2.3 \mathrm{~K}$ for the low- $\mathrm{CO}_{2}$ $\mathrm{B} 1$ scenario and from 1.5 to $4.5 \mathrm{~K}$ for the high- $\mathrm{CO}_{2} \mathrm{~A} 2$ scenario. By year 3000 , the warming increases to values from 1.5 to $3.0 \mathrm{~K}$ for $\mathrm{B} 1$ and 2.9 to $6.1 \mathrm{~K}$ for $\mathrm{A} 2$. The temperature increase after year 2100 , which we term the constant composition warming commitment, is 0.6 $1.6 \mathrm{~K}$ for $\mathrm{B} 1$ and $1.3-2.2 \mathrm{~K}$ for $\mathrm{A} 2$. In the standard case, the aerosol forcing is kept constant after the year 2100 . However, it is likely that aerosol precursor emissions decrease concomitant to the decrease in carbon emission required to stabilize the atmospheric $\mathrm{CO}_{2}$. Simulations with the Bern2.5CC EMIC show a potential additional 0.4 and $0.8 \mathrm{~K}$ warming by the year 3000 for scenarios $\mathrm{B} 1$ and $\mathrm{A} 2$, respectively, when setting the 

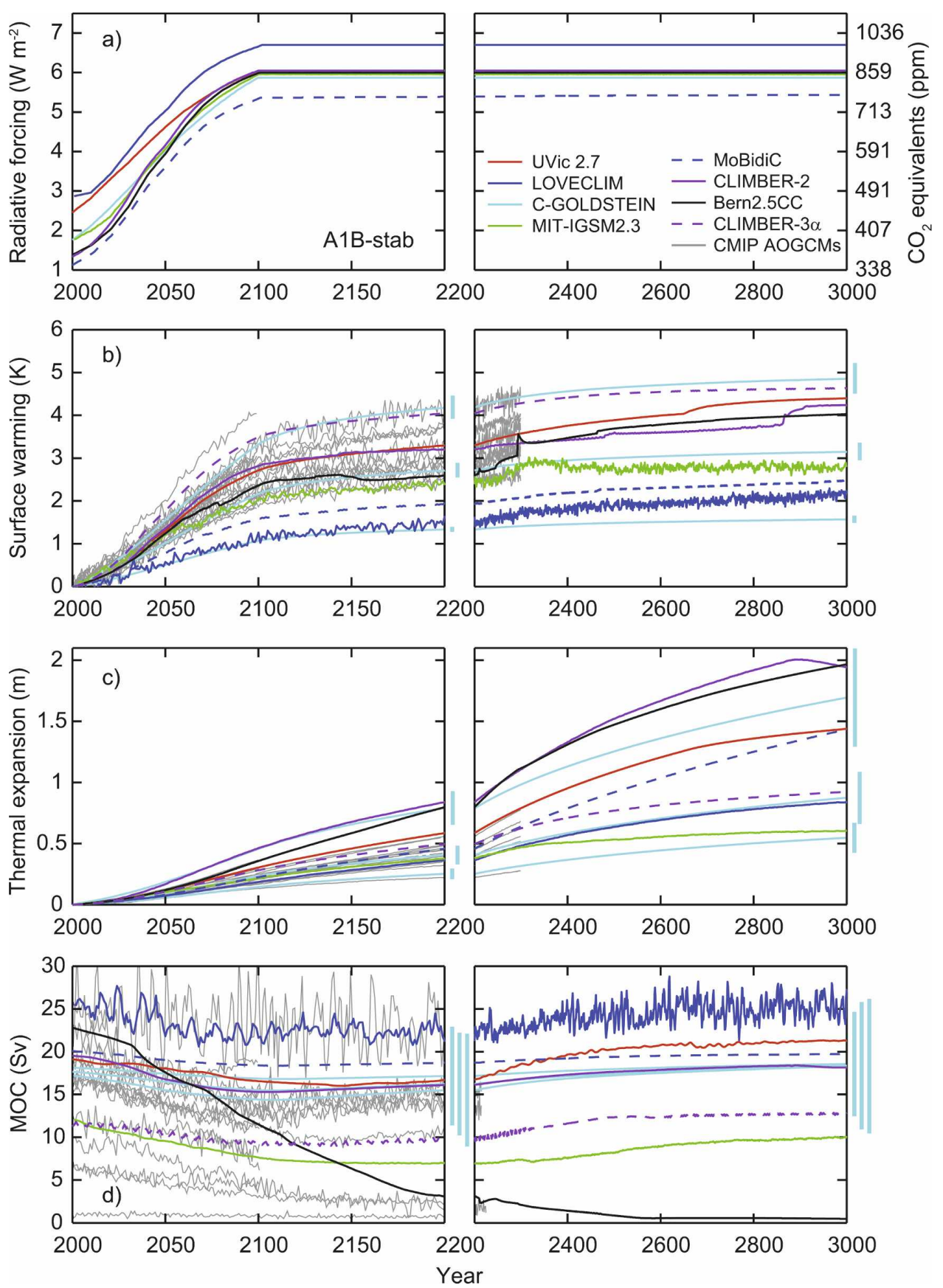

FIG. 3. (a) Radiative forcing, (b) global mean surface warming, (c) sea level rise from thermal expansion, and (d) Atlantic MOC from eight EMICs for IPCC scenario SRES A1B and stable radiative forcing after the year 2100. EMIC results (colored lines) are compared to IPCC AR4 AOGCM results (gray lines). Vertical bars to the right in (b)-(d) indicate \pm two standard deviation uncertainties due to atmosphere, ocean, and sea ice parameter perturbations in the C-GOLDSTEIN model for three ensembles with climate sensitivities of $1.5,3.0$, and $4.5 \mathrm{~K}$. In (a) the concentration of equivalent $\mathrm{CO}_{2}$ is additionally given on the right axis. The $\mathrm{CO}_{2}$ equivalents and radiative forcing are related through Eq. (1). EMIC and AOGCM modelers were free to decide on which forcing components to include in their historic runs and the future projections. As a result, radiative forcing values (and equivalents of $\mathrm{CO}_{2}$ ) differ among the models included. Anomalies in (b) and (c) are given relative to the year 2000 . 

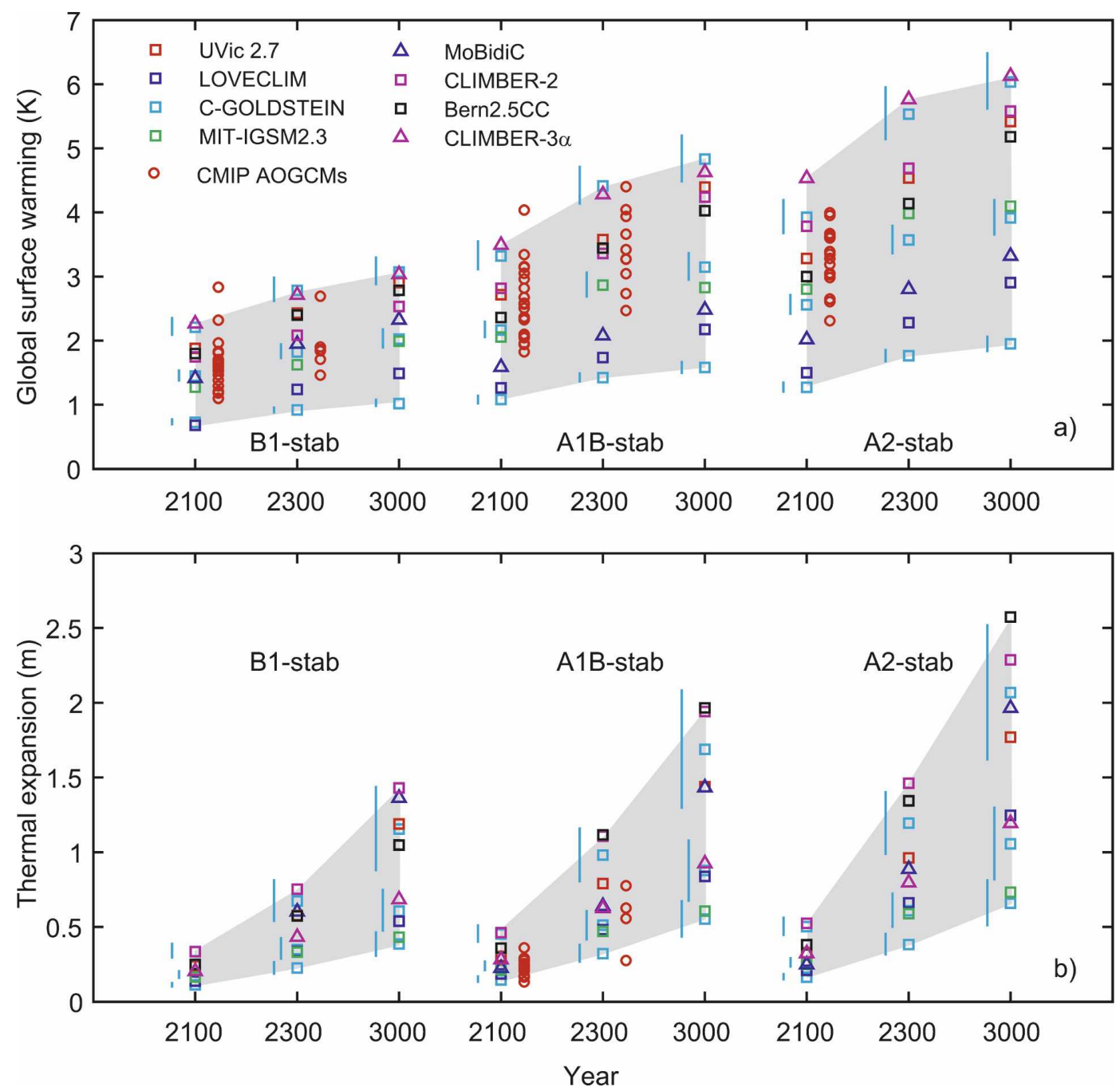

FIG. 4. (a) Global mean surface warming and (b) sea level rise from thermal expansion since the year 2000 from eight EMICs for the three IPCC illustrative SRES scenarios B1, A1B, and A2 and stable radiative forcing after the year 2100. EMIC results (colored symbols) are compared to the range from the IPCC AR4 AOGCM results (red circles). Light blue bars indicate \pm two standard deviation uncertainties due to atmosphere, ocean, and sea ice parameter perturbations in the C-GOLDSTEIN model for three ensembles with climate sensitivities of 1.5, 3.0, and 4.5 K. EMIC min-max values are highlighted by the gray-shaded area.

negative aerosol forcing $\left(\mathrm{B} 1,-0.6 \mathrm{~W} \mathrm{~m}^{-2} ; \mathrm{A} 2,-1.3 \mathrm{~W}\right.$ $\mathrm{m}^{-2}$ ) to zero after the year 2100 . The thermal expansion since the year 2000 ranges from 0.1 to $0.3 \mathrm{~m}$ for B1 and 0.2 to $0.5 \mathrm{~m}$ for A2 by 2100 . By the year 3000 , the thermal expansion increases to values from 0.4 to $1.4 \mathrm{~m}$ for B1 and 0.7 to $2.6 \mathrm{~m}$ for A2. This corresponds to a post-2100 sea level commitment of $0.3-1.1 \mathrm{~m}$ for B1 and $0.5-2.2 \mathrm{~m}$ for A2. Figure 4 also illustrates that independent of the scenario applied, the climate change commitment from the thermal expansion takes much longer to fully evolve compared to the surface warming commitment, due to the large inertia of the oceans (Meehl et al. 2005b; Wigley 2005). The wide spread of climate change commitments projected by these eight EMICs and the ranges for the perturbed physics ensembles from the C-GOLDSTEIN model clearly indicate that absolute values of projected climate change commitments for any given scenario largely depend on the specific model setup. Long-term global warming and sea level rise from thermal expansion are both mainly determined by climate sensitivity.

Comparison of these EMIC results with results from comprehensive AOGCMs up to the year 2300 in Figs. 3 and 4 indicates that the suite of EMICs generally reproduces the AOGCM behavior reasonably well on the hemispheric-to-global scale. The average levels of pro- 

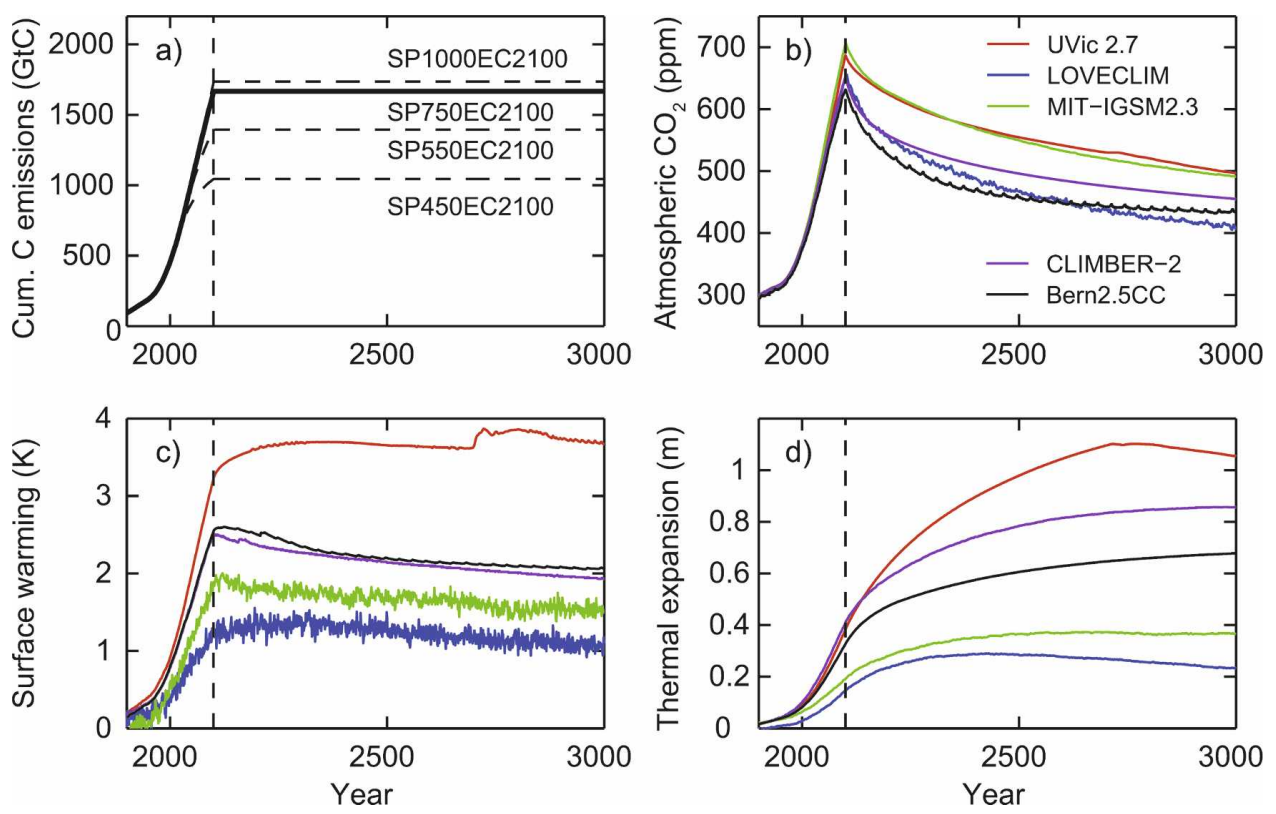

FIG. 5. Carbon emissions, atmospheric $\mathrm{CO}_{2}$, and climate response since preindustrial times for five EMICs with an interactive carbon cycle and emission pathway SP750EC2100. (a) Prescribed cumulated carbon emissions for SP750EC2100 (solid) and other emissions pathways (dashed), (b) modeled evolution of atmospheric $\mathrm{CO}_{2}$, (c) change in global mean surface air temperature, and (d) sea level rise from thermal expansion. Annual carbon emissions have been inferred from the BernCC model for different SP $\mathrm{CO}_{2}$ stabilization profiles, and set to zero after the year 2100. The small increase in surface air temperature near the year 2700 in the UVic ESCM is caused by sudden adjustments in convection sites and sea ice as the Atlantic MOC recovers to near its preindustrial value.

jected surface warming for the suite of EMICs tend to be lower than the ones from AOGCMs, whereas thermal expansions from sea level rise tend to be higher, consistent with the high EMIC ocean heat uptake efficiencies shown in Fig. 2. (Note that the number of available AOGCMs is reduced after the year 2100; thus, the AOGCM ranges at 2100 and 2300 cannot be compared directly.) On the other hand, the transient reduction of the meridional overturning circulation over the twentyfirst century in most EMICs is similar to the AOGCMs, providing further support that this class of models can be used for long-term commitment projections and probabilistic projections involving large ensemble simulations.

Recently, studies investigating constant composition commitments (Knutti et al. 2005; Matthews 2006) have used the previously introduced SP450-SP1000 $\mathrm{CO}_{2}$ stabilization profiles, where atmospheric $\mathrm{CO}_{2}$ is stabilized at levels from 450 to $1000 \mathrm{ppm}$. EMICs results for these SP stabilization profiles lead to qualitatively very similar conclusions compared with the SRES scenarios discussed above. However, the $\mathrm{CO}_{2}$ stabilization profiles allow us to investigate the effects of different shapes of $\mathrm{CO}_{2}$ stabilization pathways on climate change and climate change commitments. Stabilization profiles with a delayed turning point (DSP) or overshoot (OSP) in atmospheric $\mathrm{CO}_{2}$ concentrations have been run by all EMICs. The immediate climate change effects in these adapted stabilization profiles turn out to be very similar to the standard stabilization cases as the additional radiative forcing is relatively small (not shown). Implications for the inferred emission reductions will be discussed in section 3c (see Fig. 11). The suite of EMICs might however underestimate the climate effects due to these forcing differences as many potentially nonlinear processes are not included (e.g., ice sheet, permafrost, or ecosystem dynamics). Using an AOGCM and prescribing a larger $\mathrm{CO}_{2}$ overshoot, Tsutsui et al. (2007) found larger and longer-lasting climate effects, particularly in the ocean temperature and sea level response.

\section{b. Zero emission commitment}

The climate change commitments in response to earlier carbon emissions are investigated with the five EMICs that include interactive representations of the global carbon cycle (Figs. 5-7). Anthropogenic carbon emissions, inferred from four $\mathrm{CO}_{2}$ stabilization profiles, are prescribed until the year 2100 and set to zero thereafter until the year 3000 . No other forcing agents 

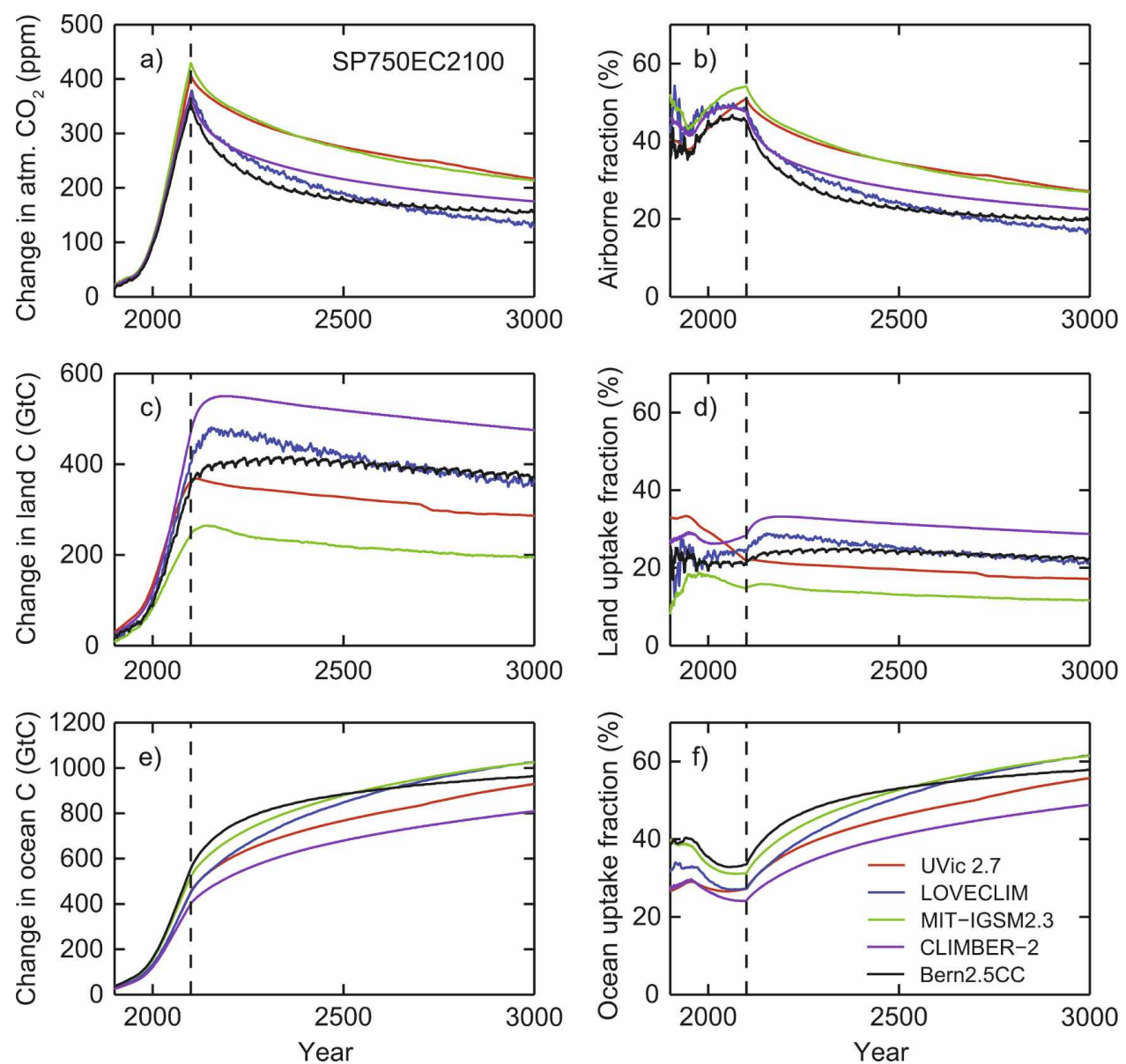

FIG. 6. Changes in carbon inventories since preindustrial times for five EMICs with an interactive carbon cycle and emission pathway SP750EC2100. (a) Modeled change in atmospheric $\mathrm{CO}_{2}$, (b) airborne fraction of $\mathrm{CO}_{2}$, (c) change in the terrestrial carbon inventory, (d) terrestrial uptake fraction of $\mathrm{CO}_{2}$, (e) change in the ocean carbon inventory, and (f) ocean uptake fraction of $\mathrm{CO}_{2}$.

have been included in these simulations. The climate and carbon cycle responses after the year 2100 are then entirely driven by changes induced by prior carbon emissions. In the following, we discuss the results for the emission pathway SP750EC2100 (Figs. 5 and 6). Atmospheric $\mathrm{CO}_{2}$ slowly decreases toward a new equilibrium level after the year 2100 as part of the excess $\mathrm{CO}_{2}$ gets taken up by the terrestrial biota and, more importantly, the ocean. The new equilibrium is not yet reached by the year 3000 in any of the models for any of the pathways applied due to the long time scale of fossil $\mathrm{CO}_{2}$ removal from the atmosphere (Kasting and Schultz 1996; Archer et al. 1997; Archer 2005). The year-3000 $\mathrm{CO}_{2}$ concentration is still substantially higher than the present concentration (370 ppm), despite the drastic (and probably unrealistic) reduction in carbon emissions. It takes between 48 and $364 \mathrm{yr}$ for the atmospheric $\mathrm{CO}_{2}$ concentration to drop from a maximum of 650-700 ppm in year 2100 to below the level of two times the preindustrial $\mathrm{CO}_{2}$. The airborne fraction of $\mathrm{CO}_{2}$, that is, the percentage of total $\mathrm{CO}_{2}$ emissions staying in the atmosphere, decreases from high values $(39 \%-55 \%)$ in year 2100 to $15 \%-27 \%$ in year 3000 . Storage of excess $\mathrm{CO}_{2}$ in the ocean is continuously becoming more important as can be seen from the increase in the ocean carbon inventory and in the ocean uptake fraction from $24 \%-34 \%$ in the year 2100 to $49 \%-62 \%$ in year 3000 . In contrast, the fraction of $\mathrm{CO}_{2}$ taken up by the terrestrial biosphere remains rather constant over time, ranging from $15 \%-29 \%$ in the year 2100 to $12 \%-29 \%$ in year 3000 . For comparison, recent results for the suite of C4MIP models and air-, landand ocean-borne fractions in the year 2100 under SRES A2 range from $42 \%$ to $71 \%$ (atmosphere), $1 \%$ to $27 \%$ (land), and $15 \%$ to $36 \%$ (ocean) (Friedlingstein et al. 2006; Denman et al. 2007). We note that ocean-sediment interactions, not included in the models, will influence the redistribution of $\mathrm{CO}_{2}$ on time scales of 

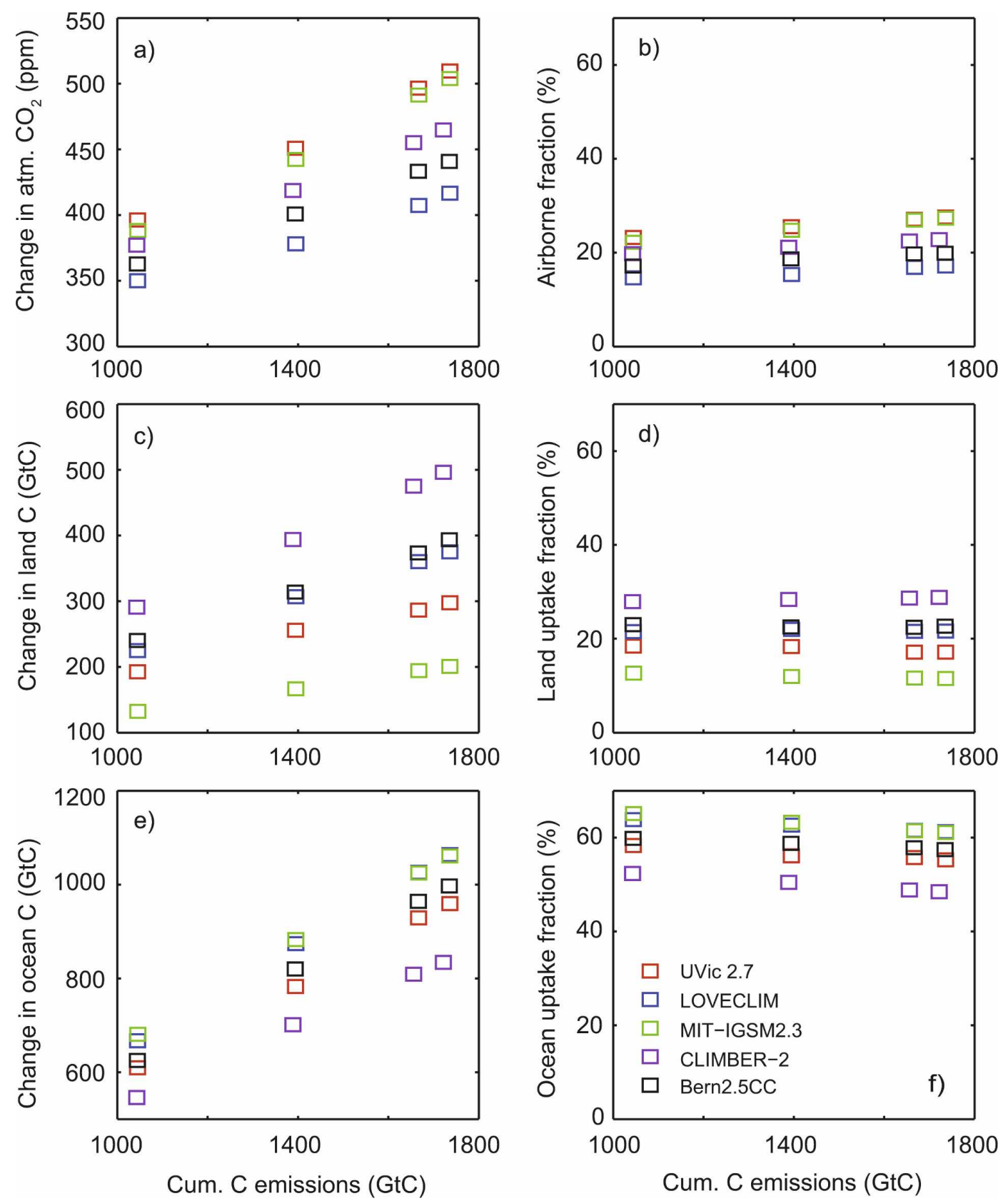

FIG. 7. Changes in carbon inventories by the year 3000 vs the total accumulated carbon emissions for five EMICs with an interactive carbon cycle and emission pathways SP450EC2100-SP1000EC2100. (a) Change in atmospheric $\mathrm{CO}_{2}$ since preindustrial times, (b) airborne fraction of $\mathrm{CO}_{2}$, (c) cumulated terrestrial carbon uptake since preindustrial times, (d) terrestrial uptake fraction of $\mathrm{CO}_{2}$, (e) cumulated oceanic carbon uptake since preindustrial times, and (f) ocean uptake fraction of $\mathrm{CO}_{2}$ at year 3000 .

millennia (Archer et al. 1997), and will further reduce atmospheric $\mathrm{CO}_{2}$ beyond the year 3000 .

Surface warming and sea level rise from thermal expansion also continue for several decades or even several centuries, with absolute values for a given pathway strongly dependent on any particular model and model setup (Fig. 5). This is qualitatively similar to what has been discussed for the SRES A1B scenario for EMICs and AOGCMs (Fig. 3). Most of the EMICs, however, start to show decreasing surface air temperature and sea level anomalies by the year 3000 for all zeroemissions pathways considered. The UVic 2.7 ESCM exhibits a stronger surface warming, caused by a combination of higher climate sensitivity compared to the 
other EMICs (but similar to many of the AOGCMs in Fig. 3) and a greater positive climate-carbon cycle feedback, partly due to decreasing surface albedo. As a consequence of the slow removal of excess $\mathrm{CO}_{2}$ from the atmosphere, emissions effected over the twenty-first century continue to impact atmospheric $\mathrm{CO}_{2}$ and climate even at year 3000 (Archer et al. 1997), and both surface temperature and sea level are still substantially higher than the preindustrial (by $1.1-3.7 \mathrm{~K}$ and $0.2-$ $1.1 \mathrm{~m}$ in SP750EC2100) and present-day values (by 0.8 $2.8 \mathrm{~K}$ and $0.2-1.0 \mathrm{~m}$ in SP750EC2100). Compared to the year 2100 , global surface temperatures are reduced by a few tenths of a degree by the year 3000 in most of the EMICs and all of the scenarios considered. In contrast, sea level in the year 3000 is still substantially higher (by $0.2-0.7 \mathrm{~m}$ for SP750EC2100) than in the year 2100 in all of the EMICs. The minimum surface warming and thermal expansion by the year 3000 compared to the present day are, respectively, $0.2 \mathrm{~K}$ and $0.2 \mathrm{~m}$ for LOVECLIM and SP450EC2100, the lowest zeroemissions pathway considered. For the projected sea level rise, however, it should be noted that none of these models includes the additional runoff from Greenland or other land-based ice sheets or glaciers. According to the IPCC AR4 AOGCM simulations, thermal expansion contributes only $70 \%-75 \%$ of the projected sea level rise in the year 2100 under the SRES emissions scenarios (Meehl et al. 2007). Including these additional contributions to global sea level would thus substantially increase the projected sea level rise and also alter the modeled temporal evolution.

Atmospheric $\mathrm{CO}_{2}$ in the year 3000 is approximately linearly related to the total amount of carbon emitted in each model, but with substantial spread among the models in both slope and absolute values (Fig. 7). For example, the projected atmospheric $\mathrm{CO}_{2}$ by the year 3000 from individual EMICs differs by more than 80 ppm in pathway SP750EC2100 (Fig. 7a), despite identical prescribed carbon emissions. This model range increases with increasing total carbon emissions. On the other hand, the airborne fraction by the year 3000 for individual EMICs remains comparatively stable among pathways (Fig. 7b). The small increase in the airborne fraction with higher $\mathrm{CO}_{2}$ emission levels is probably caused by (i) the models being still farther away from the new equilibrium in the year 3000 and (ii) stronger carbon cycle-climate feedbacks at higher $\mathrm{CO}_{2}$ levels. Overall, the relative distribution of the excess carbon among the atmosphere, ocean, and terrestrial biosphere by the year 3000 is rather constant across the different zero-emissions pathways for each individual EMIC, yet the relative contributions and numbers differ substantially between EMICs. All models find that most of the anthropogenic carbon emissions are eventually taken up by the ocean $(49 \%-62 \%)$ in the year 3000 , and that a substantial fraction $(15 \%-28 \%)$ is still airborne even after carbon emissions have ceased for $900 \mathrm{yr}$.

Finally, this zero-emissions modeling exercise also highlights the difference between a pathway toward stabilization of atmospheric $\mathrm{CO}_{2}$ concentrations as in the SP profiles, with comparatively slow reductions in $\mathrm{CO}_{2}$ emissions, and an immediate, drastic reduction in $\mathrm{CO}_{2}$ emissions as in the zero-emissions pathways. For example, for the Bern2.5CC EMIC, the atmospheric $\mathrm{CO}_{2}$ concentration in pathway SP750EC2100 and year 3000 is $433 \mathrm{ppm}$ (Fig. 5b) compared to the $750 \mathrm{ppm}$ in the $\mathrm{CO}_{2}$ stabilization profile SP750. The difference of $317 \mathrm{ppm}$ roughly corresponds to a $670-\mathrm{GtC}$ reduction in atmospheric $\mathrm{CO}_{2}$ and a total difference in the cumulated $\mathrm{CO}_{2}$ emissions of about $2640 \mathrm{GtC}$. Using Eq. (1), the atmospheric $\mathrm{CO}_{2}$ difference leads to an almost $3 \mathrm{~W} \mathrm{~m}^{-2}$ reduction in radiative forcing in the zeroemissions case compared to the stabilized concentration case. This difference in radiative forcing results in substantially different climate responses by the year 3000 , with global surface warming and a sea level rise from thermal expansion of 1.3 versus $2.2 \mathrm{~K}$ and 0.4 versus $0.7 \mathrm{~m}$ in the zero-emissions case compared to the stabilized concentration case. The larger and earlier the emission reductions, the larger the difference compared to the standard $\mathrm{CO}_{2}$ stabilization case. Overall, these results indicate that twenty-first century emissions represent a minimum commitment of climate change for several centuries, irrespective of later emissions.

\section{c. Allowed emissions for $\mathrm{CO}_{2}$ stabilization}

The amount of carbon emissions implied by a given $\mathrm{CO}_{2}$ stabilization pathway depends on how much and how efficiently carbon is taken up by the ocean and the terrestrial biosphere (Enting et al. 1994; Schimel et al. 1997; Joos et al. 2001; Prentice et al. 2001; Edmonds et al. 2004; Matthews 2006), the two major, fastresponding natural reservoirs exchanging $\mathrm{CO}_{2}$ with the atmosphere. Allowable emissions are equal to the (prescribed) change in the atmospheric carbon inventory plus the carbon uptake by land and ocean.

Projections of allowed emissions for $\mathrm{CO}_{2}$ stabilization at 550 ppm from five EMICs and the Hadley-SCM are compared in Fig. 8a. Note that the scenarios used here are idealized, and are not based on any economic model. They are used only to illustrate the response of the carbon cycle, and some scenarios might not be economically feasible or optimal. The resulting multimodel range is large, ranging from $1221 \mathrm{GtC}$ in the HadleySCM to 1918 GtC in the Bern2.5CC EMIC in year 2300 for SP550. To put these EMIC results into perspective, 

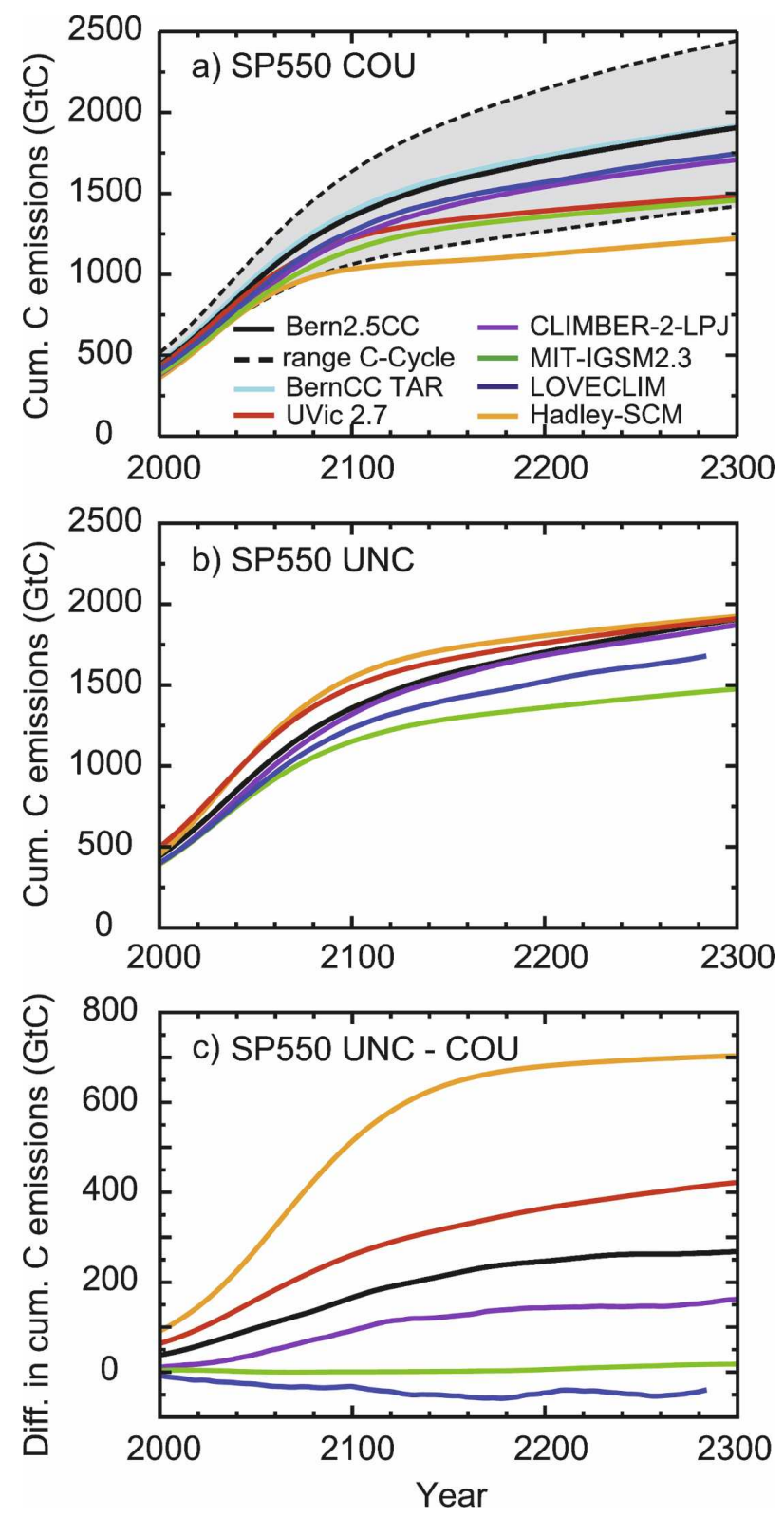

FIG. 8. Projected cumulated allowable carbon emissions leading to stabilization of atmospheric $\mathrm{CO}_{2}$ at $550 \mathrm{ppm}$ and the impact of climate change on these emissions for five IPCC AR4 EMICs with an interactive carbon cycle plus the HadleySCM. (a) Implied carbon emissions for a coupled (i.e., climate change, COU) simulation and stabilization profile SP550. (b) Implied $\mathrm{CO}_{2}$ emissions for an uncoupled (i.e., no climate change, UNC) simulation. (c) Difference between uncoupled and coupled simulations, i.e., the strength of the carbon cycleclimate feedback. Positive (negative) numbers indicate a reduction (increase) in allowed emissions if climate change is taken into account. The gray-shaded area in (a) corresponds to the Bern2.5CC range of uncertainties in the carbon cycle processes ("range C-Cycle" in Fig. 9). IPCC TAR BernCC results (turquoise solid) are also given in (a). Results for Bern2.5CC, CLIMBER-2-LPJ, MIT-IGSM2.3, and LOVECLIM are 31-yr running averages. the multimodel range for SP550 is compared to the range of carbon cycle-related uncertainty in allowable emissions from the Bern2.5CC EMIC (gray shaded area in Fig. 8a). Bern2.5CC cumulated emissions in SP550 vary between $+23 \%$ and $-29 \%$ in year 2100 $(+31 \%$ and $-31 \%$ in year 2300$)$ about the reference case. The range has been generated using assumptions about carbon cycle uncertainty as in IPCC TAR (Joos et al. 2001; Prentice et al. 2001), varying ocean transport parameters and parameterizations describing the cycling of carbon through the terrestrial biosphere. Upper bounds of allowed emissions are generated with a "fast" carbon cycle that efficiently removes excess $\mathrm{CO}_{2}$ from the atmosphere, while lower bounds are generated with a "slow" carbon cycle that is inefficient in removing excess $\mathrm{CO}_{2}$ from the atmosphere. We note that the uncertainty in climate sensitivity is not yet taken into account (for details, see the Bern2.5CC model description in appendix A). Cumulated allowed emissions from all EMICs lie between the Bern2.5CC standard setup and the setup with an inefficient carbon cycle (Fig. 8a), only the Hadley-SCM projects even lower emissions, in line with the full Hadley AOGCM (HadCM3LC; Jones et al. 2006b). The multimodel range in the year 2300 is almost as large as the uncertainty range resulting from changing carbon cycle settings in the Bern2.5CC EMIC only (1421-2443 GtC in year 2300). These large differences in the efficiency to take up additional $\mathrm{CO}_{2}$ between EMICs will be further discussed in section $3 \mathrm{~d}$.

Different sources of uncertainty in allowable carbon emissions for the stabilization profiles and the Bern2.5CC EMIC are addressed by factorial experiments (Fig. 9; illustrated for SP550). Cumulated emissions for the period from 2000 to 2100 (to 2300) range from $596 \mathrm{GtC}$ (933 GtC) for profile SP450 to $1236 \mathrm{GtC}(3052 \mathrm{GtC})$ for profile SP1000 in the standard Bern2.5CC setup. The efficient (inefficient) carbon cycle settings, in combination with an unchanged climate sensitivity of $3.2 \mathrm{~K}$, result in cumulated allowable emissions that are increased (reduced) compared to the reference case by $+29 \%(-26 \%)$ for SP450 in year $2100[+35 \%(-27 \%)$ in year 2300] and by $+20 \%(-28 \%)$ for SP1000 $[+26 \%$ $(-32 \%)$ in year 2300]. In other words, this Bern $2.5 \mathrm{CC}$ percentage uncertainty range remains roughly similar over the next few centuries and across the SP profiles.

Varying the climate sensitivity between 1.5 and $4.5 \mathrm{~K}$ while keeping all other parameters constant yields an uncertainty range in allowable emissions of $+9 \%$ to $-3 \%$ in the year 2100 for SP $450(+10 \%$ to $-5 \%$ in year $2300)$ and by $+6 \%$ to $-3 \%$ in the year 2100 for SP1000 ( $+8 \%$ to $-7 \%$ in year 2300$)$. The projected range in allowable Bern2.5CC emissions is overall very constant 


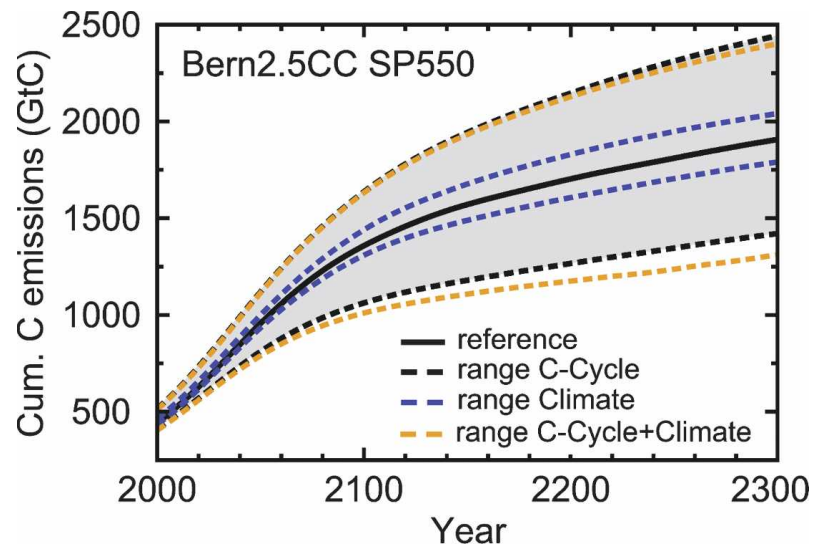

FIG. 9. Projected cumulated allowable carbon emissions leading to stabilization of atmospheric $\mathrm{CO}_{2}$ at $550 \mathrm{ppm}$ for model setups with different climate sensitivities and carbon cycle settings in the Bern2.5CC EMIC. Uncertainties in the carbon cycle processes for the Bern2.5CC EMIC are calculated as in IPCC TAR (see the text and appendix A for details). Different colored lines differentiate the separate and combined effects of the carbon cycle and climate on allowable emissions: standard, black solid; climate sensitivity of 1.5-4.5 K with standard carbon cycle, blue dashed; efficientinefficient carbon cycle at the standard climate sensitivity of $3.2 \mathrm{~K}$, black dashed line and gray-shaded area; and efficient carbon cycle-low climate sensitivity of $1.5 \mathrm{~K}$ and inefficient carbon cyclehigh climate sensitivity of $4.5 \mathrm{~K}$, orange dashed. Results are $31-\mathrm{yr}$ running averages.

over time and across the number of investigated $\mathrm{SP} \mathrm{CO}_{2}$ stabilization profiles. These Bern2.5CC ranges agree well with the UVic 2.7 results $(+12 \%$ to $-10 \%$ about the reference case in SP550 by year 2200), but are substantially larger than ranges found in the MIT-IGSM2.3 model (between $+2 \%$ and $-2 \%$ in SP550 throughout the simulation) for similar values of climate sensitivities (not shown).

Combining the lower bound for climate sensitivity $(1.5 \mathrm{~K})$ with the parameter settings for an efficient carbon cycle in the Bern2.5CC model leads to more or less unchanged upper bounds compared to the standard case $(3.2 \mathrm{~K})$ due to compensating effects of carbon storage in the terrestrial and oceanic pools. In contrast, a higher climate sensitivity of $4.5 \mathrm{~K}$ combined with an inefficient carbon cycle widens the range of allowable emissions at the lower bound. This result, illustrated in Fig. 9 for SP550, is found for all stabilization profiles considered here. The projected range of allowable emissions when combining the uncertainties is $+27 \%$ to $-32 \%$ about the reference case in the year 2100 for SP450 $(+31 \%$ to $-32 \%$ in year 2300$)$ and $+20 \%$ to $-32 \%$ in year 2100 for SP1000 $(+26 \%$ to $-40 \%$ in year 2300).

Finally, the results for the carbon cycle-related uncertainty in allowable annual emissions from the

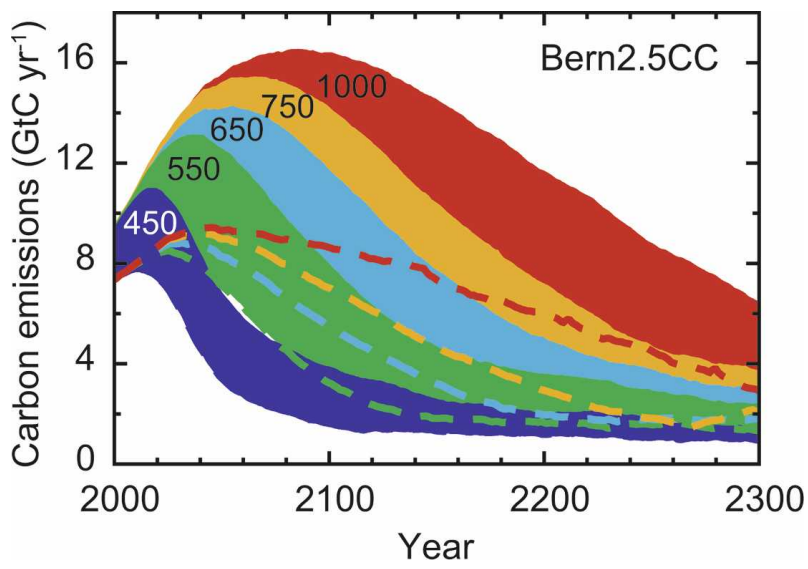

Fig. 10. Projected allowable carbon emissions leading to stabilization of atmospheric $\mathrm{CO}_{2}$ at different levels and the effects of uncertainty in carbon cycle processes on calculated emissions as projected with the Bern2.5CC EMIC. Uncertainties in the carbon cycle processes for the Bern2.5CC EMIC are calculated as in IPCC TAR (see the text and appendix A for details). Dashed lines highlight the lower bounds of the uncertainty ranges for individual profiles if otherwise hidden. Results are 31-yr running averages.

Bern2.5CC EMIC and the series of SP450-SP1000 $\mathrm{CO}_{2}$ stabilization profiles are summarized in Fig. 10. Calculated anthropogenic emissions in year 2000 for the

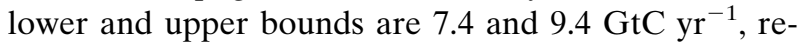
spectively, in agreement with the range of data-based estimates for the 1990s [6.4 $\pm 0.4 \mathrm{GtC} \mathrm{yr}^{-1}$ from fossil

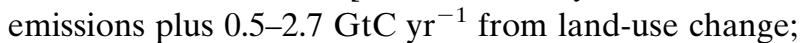
after Denman et al. (2007), based on Houghton (1999), DeFries et al. (2002), Houghton (2003), and Marland et al. (2006)]. The design of the $\mathrm{CO}_{2}$ stabilization profiles implies that projected allowed emissions continue to increase for at least another decade (lower bound SP450) to a century at most (upper bound SP1000), and then start to decline below present levels within a century or two. By the year 2300, when atmospheric $\mathrm{CO}_{2}$ is close to being stabilized in all SP profiles, the lowest and uppermost emission values required for $\mathrm{CO}_{2}$ stabilization between 450 and $1000 \mathrm{ppm}$ are 1.0 and

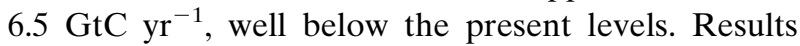
from the Bern2.5CC EMIC are very closely comparable to the BernCC results of Joos et al. (2001) included in IPCC TAR (Prentice et al. 2001) and discussed in Edmonds et al. (2004), and the small differences can be largely explained by differences in $\mathrm{CO}_{2}$ trajectories and the use of different ocean models.

These model results confirm that for the stabilization of atmospheric $\mathrm{CO}_{2}$ as prescribed in profiles SP450SP1000 (Fig. 1), the emissions need to be reduced well below the year 2000 values (Joos et al. 1999; Friedlingstein et al. 2001; Prentice et al. 2001; Edmonds et al. 

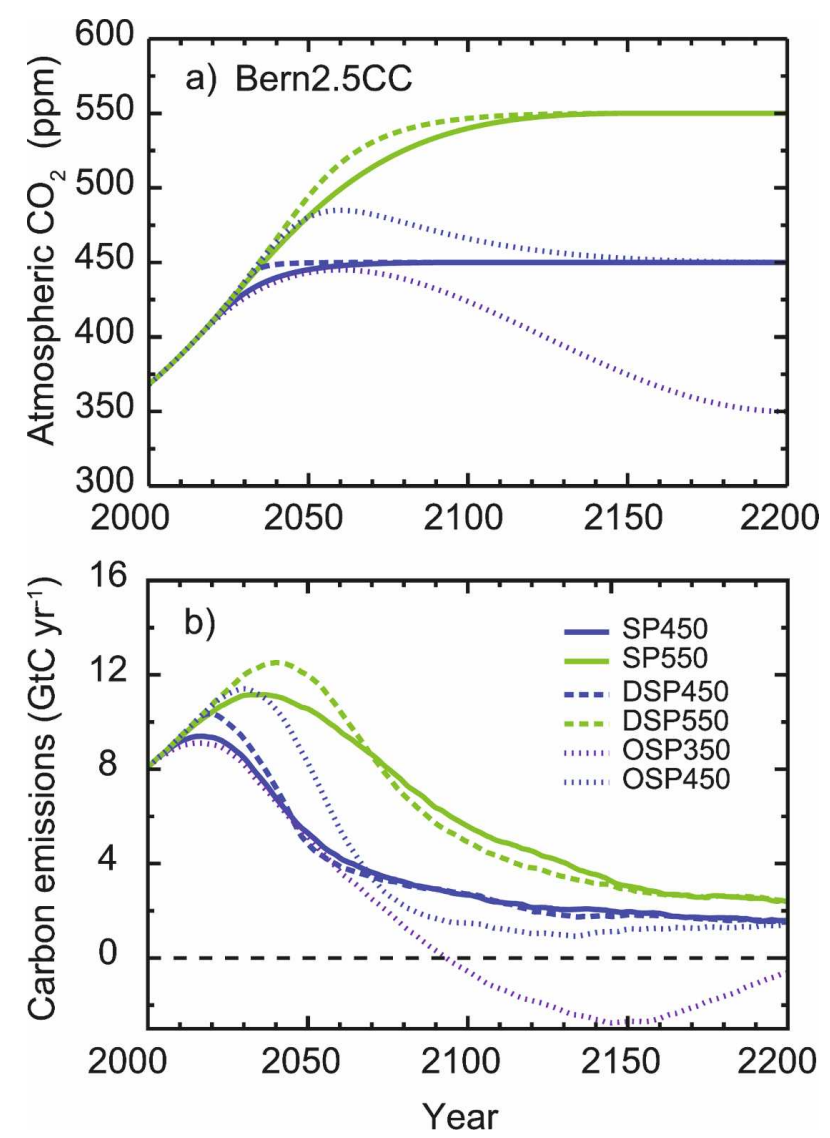

FIG. 11. Projected allowable carbon emissions leading to stabilization of atmospheric $\mathrm{CO}_{2}$ at given stabilization levels for the Bern2.5CC EMIC for different pathways leading to stabilization. (a) Assumed trajectories of $\mathrm{CO}_{2}$ concentrations in the SP, OSP, and DSP profiles. (b) Implied carbon emissions as projected with the Bern2.5CC EMIC. Profiles with the delayed turning point in the atmospheric $\mathrm{CO}_{2}$ increase (DSP) or atmospheric $\mathrm{CO}_{2}$ overshoot (OSP) are compared to the standard SP profile. Results are 31-yr running averages.

2004). This is true for the full range of $\mathrm{CO}_{2}$ stabilization simulations covering carbon cycle uncertainty, including the upper bound, which is based on rather extreme assumptions of terrestrial carbon cycle processes. This upper bound, determined by assuming no response of heterotrophic respiration to temperature changes and strong $\mathrm{CO}_{2}$ fertilization (see details in appendix A), potentially leads to unrealistically high projections of allowable $\mathrm{CO}_{2}$ emissions.

Projected allowed emissions for stabilization profiles also depend on the shape of the pathway leading to stabilization (Fig. 11). Annual $\mathrm{CO}_{2}$ emissions for the stabilization of atmospheric $\mathrm{CO}_{2}$ at $450 \mathrm{ppm}$, but with different pathways leading to stabilization (SP450 and

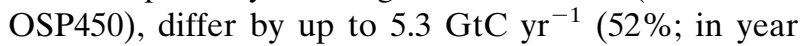
2041) in the Bern2.5CC EMIC and differences in the cumulated $\mathrm{CO}_{2}$ emissions reach a maximum of about
$130 \mathrm{GtC}$ shortly after the time of the atmospheric $\mathrm{CO}_{2}$ peak in the overshoot case around the year 2060. On a multicentury time scale, however, differences in cumulated emissions approach zero in all EMICs. Postponing actions to reduce emissions implies more stringent actions later on in order to stabilize atmospheric $\mathrm{CO}_{2}$ at a specified level. This can be seen from the steeper slopes in allowable emissions in the overshoot and delayed turning point cases compared to the standard profiles in Fig. 11. In the OSP350 case, allowable emissions even have to go below zero in the future in order to stabilize the atmospheric $\mathrm{CO}_{2}$ at $350 \mathrm{ppm}$. According to these model results, overshooting and returning to 350 ppm is therefore not possible without active $\mathrm{CO}_{2}$ removal from the atmosphere by measures such as, for example, capture and geological storage of $\mathrm{CO}_{2}$ (Hoffert et al. 2002; Lackner 2003; Harvey 2004; Haugan and Joos 2004; Keith et al. 2005). In contrast, allowable emissions for stabilization at $450 \mathrm{ppm}$ (SP450 and OSP450) remain above zero throughout the simulation in all of the EMICs.

\section{d. Model sensitivities to $\mathrm{CO}_{2}$ and climate}

To quantify the individual effects of increasing atmospheric $\mathrm{CO}_{2}$ and climate change on terrestrial and oceanic carbon storage and on allowable emissions, additional simulations have been performed for all SP profiles considered. In these simulations, $\mathrm{CO}_{2}$ was prescribed as in the standard setup ("coupled," COU), but did not affect climate ("uncoupled," UNC; Fig. 8b). The impact of increasing atmospheric $\mathrm{CO}_{2}$ is then estimated from the uncoupled simulations, whereas the magnitude of the climate-induced changes, that is, the carbon cycle-climate feedback, is estimated by differencing uncoupled and coupled runs (Fig. 8c; see section $2 \mathrm{c}$ for details).

The multimodel range in cumulated allowable emissions for the stabilization profile SP550 in the uncoupled simulations is $1476-1924$ GtC in the year 2300. This range is $36 \%$ smaller than the multimodel range in the coupled simulations, yet it is still substantial. The large differences in the uncoupled simulations highlight the need for improved representations of carbon cycle processes in these models apart from the sensitivity to climate change, a task still hampered by our current incomplete understanding of the fundamental processes driving land and ocean $\mathrm{CO}_{2}$ uptake, as alluded to in section $2 \mathrm{~d}$.

Differences in allowable emissions between uncoupled and coupled simulations vary substantially between models. Values for the six models in Fig. $8 \mathrm{c}$ and the $\mathrm{CO}_{2}$ stabilization profile SP550 range from about 0 to $+95 \mathrm{GtC}$ by the year 2000 ( $-1 \%$ to $+25 \%$ reduc- 

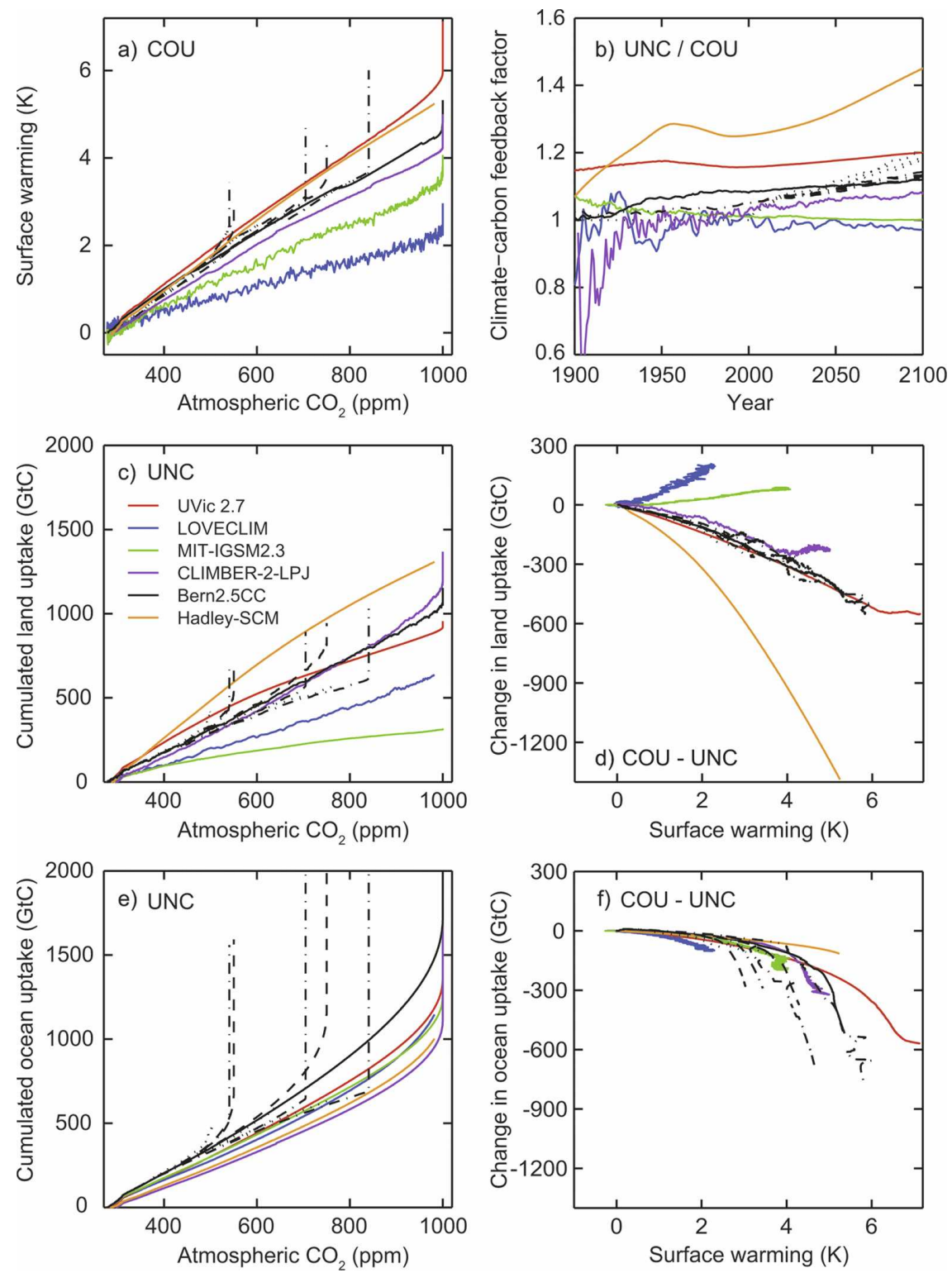

FIG. 12. Model sensitivities to increasing atmospheric $\mathrm{CO}_{2}$ and climate change for five IPCC AR4 EMICs plus the Hadley-SCM for stabilization of atmospheric $\mathrm{CO}_{2}$ at $1000 \mathrm{ppm}$ (SP1000, solid lines) following Friedlingstein et al. (2006). (a) Projected surface warming response to atmospheric $\mathrm{CO}_{2}$, (b) evolution of the carbon cycle-climate feedback factor $\xi$, (c) sensitivity of land uptake to atmospheric $\mathrm{CO}_{2}$, (d) sensitivity of land uptake to climate, (e) sensitivity of ocean uptake to atmospheric $\mathrm{CO}_{2}$, and (f) sensitivity of ocean uptake to climate. The linear sensitivity parameters $\alpha, \beta$, and $\gamma$ discussed in the main text correspond to the slopes of the lines in the different panels. The feedback factor $\xi$ is $<1$ for a negative and $>1$ for a positive carbon cycle-climate feedback. Negative numbers in (d) and (f) indicate a reduction in the cumulated fluxes due to global warming. To illustrate the sensitivity to different $\mathrm{CO}_{2}$ pathways, Bern2.5CC results for additional emission scenarios and $\mathrm{CO}_{2}$ stabilization profiles are shown: SP550 and SP750, black dashed; SRES scenarios B1, A1B, and A2 with prescribed emissions, black dotted; or prescribed $\mathrm{CO}_{2}$ held constant after the year 2100, black dashed-dotted.

tion compared to emissions from the uncoupled simulation), -33 to $+520 \mathrm{GtC}$ by year $2100(-3 \%$ to $+50 \%)$, and -33 to $+704 \mathrm{GtC}$ by year $2300(-2 \%$ to $+58 \%)$. These differences in allowable emissions imply substantial differences in atmospheric $\mathrm{CO}_{2}$ between runs with and without climate change if the emissions were prescribed. Assuming an airborne fraction of $50 \%$ in the year 2100 [see Fig. 6 or Friedlingstein et al. 
TABLE 2. EMICs model sensitivities to $\mathrm{CO}_{2}$ and climate change: standard results. Model sensitivities to increasing atmospheric $\mathrm{CO}_{2}$ (surface warming, $\alpha$; terrestrial $\mathrm{CO}_{2}$ uptake, $\beta_{L}$; oceanic $\mathrm{CO}_{2}$ uptake, $\beta_{O}$ ) and sensitivities to climate change (terrestrial $\mathrm{CO}_{2}$ uptake, $\gamma_{L}$; oceanic $\mathrm{CO}_{2}$ uptake, $\gamma_{O}$ ) have been determined using Eqs. (2)-(11). Standard EMIC results have been derived from a profile with prescribed $\mathrm{CO}_{2}$ stabilizing at $1000 \mathrm{ppm}$ (SP1000) and the year 2100. Results for the C4MIP models have been derived from a scenario with prescribed anthropogenic carbon emissions (SRES A2; Friedlingstein et al. 2006).

\begin{tabular}{|c|c|c|c|c|c|c|}
\hline Model & $\begin{array}{l}\text { Carbon cycle-climate } \\
\text { feedback factor }(\xi)\end{array}$ & $\begin{array}{c}\alpha \\
\left(\mathrm{K} \mathrm{ppm}^{-1}\right)\end{array}$ & $\begin{array}{c}\beta_{L} \\
\left(\mathrm{GtC}_{\mathrm{ppm}}^{-1}\right)\end{array}$ & $\begin{array}{c}\beta_{O} \\
\left(\mathrm{GtC}_{\mathrm{ppm}}^{-1}\right)\end{array}$ & $\begin{array}{c}\gamma_{L} \\
\left(\mathrm{GtC} \mathrm{K}^{-1}\right)\end{array}$ & $\begin{array}{c}\gamma_{O} \\
\left(\mathrm{GtC} \mathrm{K}^{-1}\right)\end{array}$ \\
\hline \multicolumn{7}{|c|}{ EMICs standard: SP1000 for the year 2100} \\
\hline Bern2.5CC & 1.12 & 0.0070 & 1.42 & 1.63 & -64 & -15 \\
\hline CLIMBER-2-LPJ & 1.08 & 0.0067 & 1.43 & 1.11 & -38 & -12 \\
\hline LOVECLIM & 0.97 & 0.0028 & 0.83 & 1.26 & 83 & -31 \\
\hline MIT-IGSM2.3 & 1.00 & 0.0051 & 0.55 & 1.34 & 13 & -14 \\
\hline UVic 2.7 & 1.20 & 0.0082 & 1.56 & 1.39 & -75 & -28 \\
\hline Hadley-SCM & 1.45 & 0.0081 & 2.19 & 1.15 & -195 & -14 \\
\hline EMIC MEAN & 1.14 & 0.0063 & 1.33 & 1.31 & -46 & -19 \\
\hline EMIC RANGE & 0.97 to 1.45 & 0.0028 to 0.0082 & 0.55 to 2.19 & 1.11 to 1.63 & 83 to -195 & -12 to -31 \\
\hline \multicolumn{7}{|c|}{ C4MIP models: SRES A2 for the year 2100} \\
\hline C4MIP MEAN & 1.18 & 0.0061 & 1.35 & 1.13 & -79 & -30 \\
\hline C4MIP RANGE & 1.04 to 1.44 & 0.0038 to 0.0072 & 0.2 to 2.8 & 0.8 to 1.6 & -20 to -177 & -14 to -67 \\
\hline
\end{tabular}

(2006)] implies an additional 44-245 ppm of atmospheric $\mathrm{CO}_{2}$. Results for SP750 and SP1000 (not shown) indicate that the percent differences in the allowable emissions between coupled and uncoupled simulations increase with higher levels of $\mathrm{CO}_{2}$ stabilization. For stabilization at $1000 \mathrm{ppm}$ and the year 2300, for example, climate change reduces the allowable emissions in models with a positive feedback between $12 \%$ and $66 \%$. These numbers are in the same range as numbers reported in previous studies investigating carbon cycleclimate feedbacks and their effects on atmospheric $\mathrm{CO}_{2}$ or allowable emissions in future scenarios (Sarmiento et al. 1998; Joos et al. 1999; Matear et al. 2000; Joos et al. 2001; Plattner et al. 2001; Friedlingstein et al. 2001; Cox et al. 2000; Jones et al. 2006b; Friedlingstein et al. 2006).

We analyze model sensitivities to increasing atmospheric $\mathrm{CO}_{2}$ and to climate change using Eqs. (2)-(9), introduced in section 2c. Results for simulations with prescribed atmospheric $\mathrm{CO}_{2}$ concentrations are presented in Figs. 8 and 12 and are listed in Tables 2 and 3. We will show that using results from prescribed concentration scenarios to determine carbon cycle sensitivities to $\mathrm{CO}_{2}$ and climate may be preferable to using results from emission scenarios, as was done in the method of Friedlingstein et al. (2006).

Four out of the six models show the expected result of a positive carbon cycle-climate feedback (Friedlingstein et al. 2006). One model shows almost no difference (MIT-IGSM2.3) and one model even produces a negative feedback (LOVECLIM) with higher emissions in the coupled run (Fig. 8c). The terrestrial biosphere module VECODE (Brovkin et al. 2002) used in LOVECLIM simulates an increase in net primary productivity (NPP) due to the warming in the case of ample moisture. As precipitation increases with warming in the physical model, NPP increases in the coupled simulation. The nearly absent feedback in MITIGSM2.3 also results from an increase in $\mathrm{CO}_{2}$ uptake by the terrestrial biosphere under global warming. The latter occurs because the uptake of atmospheric $\mathrm{CO}_{2}$ by plants in the Terrestrial Ecosystems Model (TEM) is assumed to be constrained by nitrogen availability (McGuire et al. 1992; Melillo et al. 1993). If global warming is accounted for, then the enhanced nitrogen mineralization will alleviate the nitrogen constraint and allow all ecosystems, including boreal and temperate forests, to benefit more from $\mathrm{CO}_{2}$ fertilization. Using TEM without interactive carbon-nitrogen coupling results in reduced terrestrial carbon uptake under climate change (Sokolov et al. 2008), similar to the results seen in the other terrestrial ecosystem models.

Surface warming, cumulated carbon uptake by the terrestrial biosphere, and cumulated carbon uptake by the ocean all increase with increasing $\mathrm{CO}_{2}$ and show a close-to-linear dependence on atmospheric $\mathrm{CO}_{2}$ in stabilization profile SP1000, except when $\mathrm{CO}_{2}$ approaches stabilization (the "vertical" part at the end of the simulations in Fig. 12a, 12c, and 12e). The multimodel range in $\beta$, the carbon sensitivity parameter to increasing $\mathrm{CO}_{2}$, is substantially larger for the terrestrial biosphere component than for the ocean component (Table 2). This is consistent with the findings of Edmonds et al. (2004) and Friedlingstein et al. (2006), showing that uncertainties in model-derived allowable emissions by the year 2100 are to a large extent determined by uncertainties in land carbon cycling.

Climate change, on average, leads to a reduction in carbon storage in both land and ocean (Figs. 12d and 


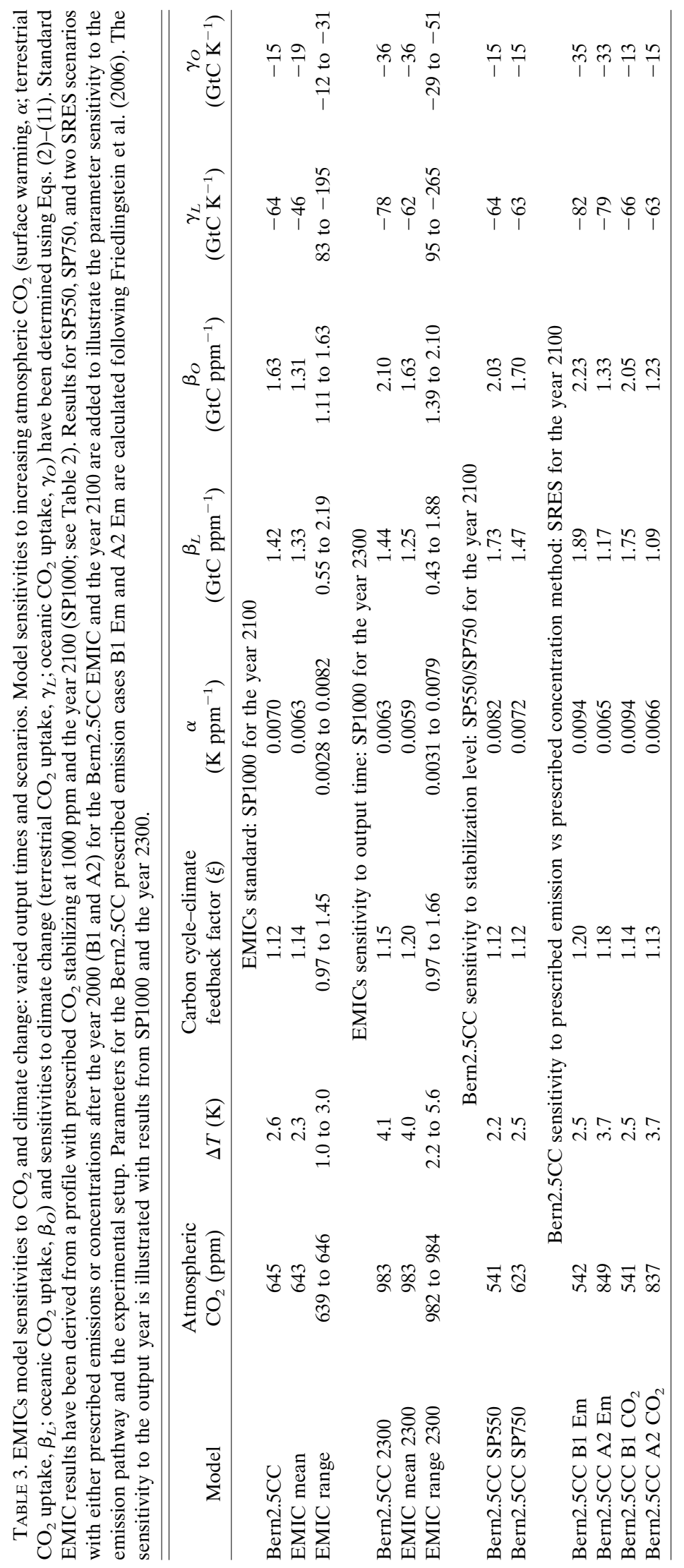


12f; Table 2). Notable exceptions are the MIT-IGSM2.3 and LOVECLIM EMICs discussed earlier, which project terrestrial carbon storage to increase with changing climate. These EMIC sensitivities to climate translate into a mean sensitivity of cumulated allowed carbon emissions to climate of $-66 \mathrm{GtC} \mathrm{K}^{-1}$ (EMIC range: +46 to -209$)$. The terrestrial biosphere response to climate change dominates the overall carbon cycle-climate feedback over the first centuries of the simulations, but the ocean becomes continuously more important as can be seen from the increasing slopes in Fig. 12f.

To determine how the exact definition and the applied scenario affect the calculated model sensitivity parameters, we have examined the results for additional SP stabilization profiles, SRES scenarios with prescribed $\mathrm{CO}_{2}$, and SRES scenarios with prescribed emissions for the Bern2.5CC EMIC. The choice of scenario, method of calculation (prescribed emissions versus prescribed concentration), and time of evaluation can substantially affect results (Fig. 12; Table 3).

The sensitivity of the global mean surface air temperature to changing atmospheric $\mathrm{CO}_{2}, \alpha$, tends to be smaller in scenarios with higher total atmospheric $\mathrm{CO}_{2}$ levels and faster rates of increase in $\mathrm{CO}_{2}$. Note that $\alpha$ is reduced by over $30 \%$ in the year 2100 and SRES A2 compared to B1. Both $\beta_{L}$ and $\beta_{O}$ are smaller for high than for low carbon emissions or atmospheric $\mathrm{CO}_{2}$ concentration scenarios. For example, $\beta_{L}$ and $\beta_{O}$ are about $40 \%$ smaller in SRES A2 compared to B1 at year 2100. These differences in the sensitivities of land and ocean carbon uptake to $\mathrm{CO}_{2}$ point to strong nonlinearities in the carbon cycle related, for example, to system time lags, the carbonate chemistry in the ocean, or $\mathrm{CO}_{2}$ fertilization on land. These nonlinearities need to be properly accounted for when evaluating the carbon cycleclimate feedback.

The carbon sensitivities to climate change, $\xi, \gamma_{L}$, and $\gamma_{O}$, are hardly affected by the choice of scenario when either carbon emissions or atmospheric $\mathrm{CO}_{2}$ concentrations are prescribed. In contrast, differences in $\gamma$ values evaluated from scenarios with prescribed carbon emissions and prescribed $\mathrm{CO}_{2}$ concentrations are surprisingly large. While differences in the $\beta_{L}$ and $\beta_{O}$ values between these two setups are comparatively modest ( $7 \%$ and $8 \%$, respectively) and explained by different $\mathrm{CO}_{2}$ concentrations in the uncoupled simulations, differences in $\gamma_{L}(20 \%)$ and, in particular, in $\gamma_{O}$ values $(55 \%-63 \%)$ are substantial (Table 3$)$. These differences in $\gamma$ arise from methodological differences between the two approaches. In the prescribed $\mathrm{CO}_{2}$ concentration case, $\gamma$ can be directly determined from the difference between coupled and uncoupled simulations [see Eqs. (6) and (7)]. In contrast, in the prescribed carbon emissions case, $\beta$ is needed to separate the climate-only effect from the combined climate plus $\mathrm{CO}_{2}$ effect on the ocean and land carbon uptake. According to Friedlingstein et al. (2006), $\gamma_{L}$ and $\gamma_{O}$ are then calculated as

$$
\gamma_{L}=\left[\left(\Delta C_{L}^{\mathrm{cou}}-\Delta C_{L}^{\mathrm{unc}}\right)-\beta_{L}\left(\Delta C_{A}^{\mathrm{cou}}-\Delta C_{A}^{\mathrm{unc}}\right)\right] / \Delta T_{A}^{\mathrm{cou}}
$$

and

$\gamma_{O}=\left[\left(\Delta C_{O}^{\mathrm{cou}}-\Delta C_{O}^{\mathrm{unc}}\right)-\beta_{O}\left(\Delta C_{A}^{\mathrm{cou}}-\Delta C_{A}^{\mathrm{unc}}\right)\right] / \Delta T_{A}^{\mathrm{cou}}$,

respectively. The land and ocean sensitivities to the total $\mathrm{CO}_{2}$ increase over the entire simulation are represented by $\beta_{L}$ and $\beta_{O}$, respectively. However, more appropriate is to apply $\beta$ values representative for the additional, carbon cycle-climate feedback induced $\mathrm{CO}_{2}$ increase only, $\beta_{L}^{\Delta}$ and $\beta_{O}^{\Delta}$, respectively. In other words, the magnitude of the climate impact on land and ocean carbon uptakes is overestimated by Friedlingstein et al. (2006) and Denman et al. (2007). Non-climate-related nonlinearities in the land and ocean carbon cycle are partly attributed to climate change when using the method of Friedlingstein et al. (2006).

To illustrate the magnitude of this effect, we approximate $\beta^{\Delta}$ using differences in the SRES scenarios as an analog for the carbon cycle-climate feedback induced $\mathrm{CO}_{2}$ difference for a specific scenario. We use Eq. (5) for the ocean component [or analogously, Eq. (4) for the land] and write for scenario A2,

$$
\Delta C_{O}^{\mathrm{unc}, \mathrm{A} 2}=\beta_{O}^{A 2} \Delta C_{A}^{\mathrm{unc}, \mathrm{A} 2} .
$$

Here, $\Delta C_{O}^{\text {unc, } A 2}$ can also be expressed as a combination of the change in ocean carbon inventory due to increasing $\mathrm{CO}_{2}$ in scenario $\mathrm{B} 1$, plus an additional, marginal contribution from the difference in the atmospheric $\mathrm{CO}_{2}$ between $\mathrm{B} 1$ and $\mathrm{A} 2$ :

$$
\Delta C_{O}^{\mathrm{unc}, \mathrm{A} 2}=\beta_{O}^{\mathrm{B} 1} \Delta C_{A}^{\mathrm{unc}, \mathrm{B} 1}+\beta_{O}^{\Delta(\mathrm{A} 2-\mathrm{B} 1)} \Delta \Delta C_{A}^{\mathrm{unc}(\mathrm{A} 2-\mathrm{B} 1)},
$$

where $\Delta \Delta C_{A}^{\mathrm{unc}(A 2-B 1)}$ represents the difference in the atmospheric $\mathrm{CO}_{2}$ between SRES A2 and B1 in the uncoupled simulation. Combining and rearranging Eqs. (12) and (13) then leads to the following expression for $\beta_{O}^{\Delta}$ :

$$
\begin{aligned}
\beta_{O}^{\Delta(\mathrm{A} 2-\mathrm{B} 1)}= & \left(\beta_{O}^{\mathrm{A} 2} \Delta C_{A}^{\mathrm{unc}, \mathrm{A} 2}\right. \\
& \left.-\beta_{O}^{\mathrm{B} 1} \Delta C_{A}^{\mathrm{unc}, \mathrm{B} 1}\right) / \Delta \Delta C_{A}^{\mathrm{unc},(\mathrm{A} 2-\mathrm{B} 1)} .
\end{aligned}
$$

The $\beta^{\Delta}$ values determined from the Bern2.5CC model simulations for SRES scenarios B1 and A2 are reduced by $57 \%$ and $51 \%$ for land and ocean, respectively, compared to the $\beta_{L}$ and $\beta_{O}$ values calculated following 
Friedlingstein et al. (2006). Consequently, replacing $\beta$ with $\beta^{\Delta}$ in Eqs. (10) and (11) for scenarios forced by prescribed carbon emissions leads to less negative values for both $\gamma_{L}$ (reduced by 18\%) and $\gamma_{O}$ (reduced by $53 \%$ ), overall resulting in a closer agreement with scenarios where $\mathrm{CO}_{2}$ concentrations are prescribed.

In summary, the results reported here for a range of EMICs indicate that these model sensitivity parameters are generally neither constant over time within one specific model and scenario nor constant across scenarios with different carbon emission or atmospheric $\mathrm{CO}_{2}$ concentration pathways. The carbon sensitivities to climate change $\left(\xi, \gamma_{L}\right.$, and $\left.\gamma_{O}\right)$, while being rather constant across scenarios with different $\mathrm{CO}_{2}$ levels, strongly depend on the scenario setup, with either prescribed carbon emissions or prescribed atmospheric $\mathrm{CO}_{2}$ concentrations, and the associated parameter calculation method. These differences in the sensitivity parameters need to be kept in mind when comparing results from different studies.

\section{Conclusions}

We have projected climate change commitments and carbon cycle-related uncertainty in future allowable emissions over the twenty-first century and up to the year 3000 for a wide range of scenarios using eight Earth System Models of Intermediate Complexity (EMICs) and the Hadley-SCM. The suite of cost-efficient EMICs overall proves well suited to complement more complex and computationally expensive models.

Simulated surface warming, thermal expansion, and the strength of the Atlantic meridional overturning circulation from the group of EMICs and IPCC illustrative SRES scenarios until years 2100 and 2300 are in good agreement with the results from more comprehensive models used in the recent IPCC Fourth Assessment Report (Randall et al. 2007; Meehl et al. 2007). The equilibrium climate sensitivity, transient climate response, and ocean heat uptake efficiency of the contributing EMICs range between 1.9 and $4.3 \mathrm{~K}, 0.9$ and $2.3 \mathrm{~K}$, and 0.6 and $1.1 \mathrm{~W} \mathrm{~m}^{-2} \mathrm{~K}^{-1}$, results that are comparable to the corresponding AOGCM ranges.

Surface warming and thermal expansion are substantial for scenarios with constant atmospheric composition and radiative forcing after the year 2100 . Constant composition commitments by the year 3000 under the high- $\mathrm{CO}_{2}$ SRES A2 scenario are up to $2.2 \mathrm{~K}$ for global mean surface air temperature and up to $2.2 \mathrm{~m}$ for thermal expansion, respectively. Stabilizing radiative forcing after the year 2100 will clearly not lead to stabilization of climate change on a century time scale, even less so when a potential reduction in the (negative) aerosol radiative forcing by emission reduction toward
$\mathrm{CO}_{2}$ stabilization is taken into account. Thermal expansion in particular continues for several centuries in all EMICs.

Emissions over the twenty-first century will substantially affect climate over the next millennium and beyond. Atmospheric $\mathrm{CO}_{2}$, radiative forcing, and temperature remain high for at least another millennium even when carbon emissions are hypothetically set to zero after the year 2100. By the year 3000, sea level is still rising due to ongoing thermal expansion of ocean waters, with a post- 2100 commitment of $0.1-0.7 \mathrm{~m}$ for the zero-emissions pathway SP750EC2100. Global surface air temperatures remain high and are reduced by a few tenths of a degree only by the year 3000 compared to the year 2100 in most EMICs and zero-emissions scenarios considered.

The redistribution of anthropogenic $\mathrm{CO}_{2}$ emitted into the atmosphere is found to be largely model dependent, yet rather constant for a specific model across a range of scenarios. The EMIC ranges for airborne $(39 \%-55 \%)$, ocean $(24 \%-34 \%)$, and land $(15 \%-29 \%)$ uptake fractions of $\mathrm{CO}_{2}$ by the year 2100 and SP750 compare reasonably well to the range for the C4MIP models and SRES scenario A2 (Denman et al. 2007; Friedlingstein et al. 2006). The ocean uptake fraction is increasing over time in all of the EMICs and, on long time scales, most of the excess $\mathrm{CO}_{2}$ thus ends up being taken up by the ocean. Nevertheless, in the year 3000 a substantial fraction $(15 \%-28 \%)$ is still airborne even after carbon emissions have stopped $900 \mathrm{yr}$ earlier.

Allowable emissions for the stabilization of $\mathrm{CO}_{2}$ at levels between 450 and 1000 ppm according to the applied SP profiles need to be reduced in all EMICs well below present levels to allow for future stabilization of atmospheric $\mathrm{CO}_{2}$ (Joos et al. 2001; Prentice et al. 2001; Edmonds et al. 2004; Matthews 2006). Our simulations also show that postponing actions to reduce emissions implies the need for more stringent actions later on in order to stabilize the atmospheric $\mathrm{CO}_{2}$ at a specified level. These conclusions are robust across the range of models and model settings. They do not depend on climate sensitivity or carbon cycle settings as is shown with the sensitivity simulations using the Bern2.5CC EMIC. Climate sensitivity and carbon cycle uncertainties in this particular EMIC translate into combined uncertainties in allowable emissions ranging from $-34 \%$ to $27 \%$ by year 2100 and $-41 \%$ to $+31 \%$ by year 2300 across all SP $\mathrm{CO}_{2}$ stabilization profiles, slightly increasing over time as climate change progresses and when moving to higher emissions and stabilization targets.

The impact of climate-sensitivity-related uncertainty on projected allowable emissions for a given $\mathrm{CO}_{2}$ sta- 
bilization target is substantially smaller than the uncertainty related to different carbon cycle settings in the Bern2.5CC EMIC. This result is in line with the results from Joos et al. (2001) included in Prentice et al. (2001), but opposite to the results of Jones et al. (2006a) obtained with the Hadley-SCM. The relative causes of this uncertainty are still being researched, but might also depend on the specific scenario setup. Results from Caldeira et al. (2003) showed that under prescribed $\mathrm{CO}_{2}$ emissions aiming for a specified temperature target, as opposed to a specific $\mathrm{CO}_{2}$ target, climatesensitivity-related uncertainty is dominant.

The suite of EMICs exhibits large differences, particularly with regard to the sensitivity of terrestrial carbon uptake to $\mathrm{CO}_{2}$ and climate. The multimodel EMIC range is found to be almost as large as the uncertainty range from the Bern $2.5 \mathrm{CC}$ only, obtained by combining different bounding assumptions about the behavior of processes driving the land and ocean $\mathrm{CO}_{2}$ uptake. The large model spread in land and ocean carbon uptake for the uncoupled simulations, where climate change is not accounted for, point to the importance of improving our understanding of the underlying processes driving terrestrial and oceanic $\mathrm{CO}_{2}$ uptake, apart from the sensitivity to climate change, and highlight the need for better carbon cycle representations in these models.

On average, the EMICs produce a positive carbon cycle-climate feedback, reducing the efficiency of the ocean and terrestrial biosphere to take up anthropogenic $\mathrm{CO}_{2}$, leading to even lower allowable emissions if climate change is accounted for. However, two EMICs show either an unexpectedly small or an even negative carbon cycle-climate feedback, caused by the terrestrial biosphere response to climate change. These results are at odds with previous modeling studies investigating carbon cycle-climate feedbacks (Cox et al. 2000; Friedlingstein et al. 2001; Joos et al. 2001; Prentice et al. 2001; Gerber et al. 2004; Friedlingstein et al. 2006).

The strength of carbon cycle-climate feedbacks in the EMICs, and the sensitivities of ocean $\mathrm{CO}_{2}$ uptake and terrestrial $\mathrm{CO}_{2}$ uptake to climate change and increasing atmospheric $\mathrm{CO}_{2}$ by the year 2100 , are comparable to previous C4MIP results (Friedlingstein et al. 2006), except for the two EMICs with an overall small or negative feedback. Sensitivity simulations with the Bern2.5CC EMIC indicate that these carbon cycle sensitivity parameters are not constant over time within one specific model and scenario and do depend on the choice of scenario. It may be preferable to calculate the carbon cycle sensitivity parameters and the strength of the carbon cycle-climate feedback from simulations with prescribed $\mathrm{CO}_{2}$ concentrations to properly ac- count for non-climate-related nonlinearities in the carbon cycle.

In summary, EMICs can be used to project long-term climate change commitments and to investigate the evolution of globally averaged quantities. Our results can be expected to closely agree with the results from more comprehensive models. We suggest that a strong emphasis in future studies using EMICs should be on estimating probabilistic uncertainties in climate change and carbon cycle commitments. The possibility of performing multiple sensitivity and ensemble simulations with individual models in addition to analyzing multimodel ranges is one of the advantages of using EMICs compared to AOGCMs.

Acknowledgments. This work was funded by the Swiss National Science Foundation, the Swiss Federal Office for the Environment, EU projects CARBOOCEAN (511176-2) and EUROCEANS (511106-2), and GAINS ASIA (022652). Both ED and AM acknowledge support from the Belgian Federal Science Policy within its Research Programme on Science for a Sustainable Development. CDJ was supported by the U.K. Department for Environment, Food, and Rural Affairs under Contract PECD 7/12/37. MFL was funded by the Fonds National de la Recherche Scientifique (Belgium) through the Fonds de la Recherche Fondamentale Collective; SN was funded through the James S. McDonnell Foundation Centennial Fellowship. AJW, ME, and HDM acknowledge research grant funding from CFCAS. We acknowledge the international modeling groups for providing their AOGCM data for analysis, the Program for Climate Model Diagnosis and Intercomparison (PCMDI) for collecting and archiving the model data, the JSC/CLIVAR Working Group on Coupled Modeling (WGCM) and their Coupled Model Intercomparison Project (CMIP) and Climate Simulation Panel for organizing the model data analysis activity, and the IPCC WG1 TSU for technical support. The IPCC Data Archive at Lawrence Livermore National Laboratory is supported by the Office of Science, U.S. Department of Energy. We appreciate the comments of Klaus Keller and two anonymous reviewers.

\section{APPENDIX A}

\section{Earth System Models of Intermediate Complexity}

The eight Earth System Models of Intermediate Complexity (EMICs) that contributed output to the IPCC AR4 intercomparison are listed in Table 1 of the main text. Short descriptive paragraphs of all EMICs and the Hadley-SCM are given below. More information on individual models can be found in the original literature. The suite of EMICs covers a wide range of 
complexities and individual models account for varying numbers of earth system components. The resulting spread in available EMIC model projections can be viewed as representative for the whole EMICs community at this time.

\section{BERN2.5CC}

The Bern2.5CC reduced complexity climate model includes components describing 1) the physical climate system, 2) the cycling of carbon and related elements, and 3) a module to calculate concentrations of non- $\mathrm{CO}_{2}$ greenhouse gases and radiative forcing by atmospheric $\mathrm{CO}_{2}$, non- $\mathrm{CO}_{2}$ greenhouse gases, and aerosols (Plattner et al. 2001; Joos et al. 2001). The ocean physical component is the zonally averaged, three-basin circulation model of Stocker et al. (1992), coupled to a zonally and vertically averaged atmospheric energy balance model, including an active hydrological cycle (Schmittner and Stocker 1999). The ocean biogeochemical component includes a simple prognostic description of the cycles of carbon, carbon isotopes, oxygen, and carbon-related tracers (Marchal et al. 1998; Plattner et al. 2001). The terrestrial biosphere component is the Lund-PotsdamJena (LPJ) dynamic global vegetation model at $3.75^{\circ} \times$ $2.5^{\circ}$ resolution as used by Joos et al. (2001), Gerber et al. (2003), and described in detail by Cramer et al. (2001), Sitch et al. (2003), and McGuire et al. (2001). Fertilization of plants by increasing atmospheric $\mathrm{CO}_{2}$ concentrations is modeled according to the modified Farquhar scheme (Farquhar et al. 1980). The module designed to calculate radiative forcing by atmospheric $\mathrm{CO}_{2}$, non- $\mathrm{CO}_{2}$ greenhouse gases, and aerosols is based on work summarized in Fuglestvedt and Berntsen (1999) and Joos et al. (2001).

\section{1) BERn2.5CC SETUPS FOR SENSITIVITY RUNS}

The Bern2.5CC model ranges shown in Figs. 9 and 10 were obtained by combining different bounding assumptions about the behavior of the $\mathrm{CO}_{2}$ fertilization effect, the response of heterotrophic respiration to temperature, and the turnover time of the ocean, thus approaching an upper bound of uncertainties in the carbon cycle. The approach applied here is identical to the one used in IPCC TAR (Joos et al. 2001; Prentice et al. 2001): the low- $\mathrm{CO}_{2}$ case was obtained by applying an efficiently mixing ocean and assuming heterotrophic respiration to be independent of global warming, and the high- $\mathrm{CO}_{2}$ case was obtained by applying an inefficiently mixing ocean and capping $\mathrm{CO}_{2}$ fertilization after the year 2000. Calculated anthropogenic emissions in the year 2000 for the lower and upper bounds are 7.4 and $9.4 \mathrm{GtC} \mathrm{yr}^{-1}$, respectively, in accord with the range of data-based estimates for the 1990s [6.4 $\pm 0.4 \mathrm{GtC}$

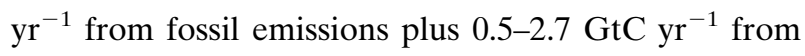
land-use change; after Denman et al. (2007), based on Houghton (1999), DeFries et al. (2002), Houghton (2003), and Marland et al. (2006)]. The average ocean carbon uptake over the 1980-2000 period ranges be-

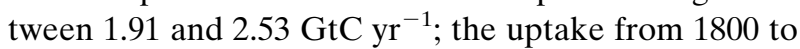
1995 is between 116.1 and $159.8 \mathrm{GtC}$, and thus at the upper end of the current range of observational estimates (Le Quéré et al. 2003; Sabine et al. 2004a,b; Manning and Keeling 2006). The effect of varying climate sensitivity from 1.5 to $4.5 \mathrm{~K}$ has been taken into account additionally. The model reference case is obtained with the midrange behavior of the carbon cycle and a climate sensitivity of $3.2 \mathrm{~K}$.

\section{2) C-GOLDSTEIN}

C-GOLDSTEIN is described in detail by Edwards and Marsh (2005). It is a dynamically simplified oceanatmosphere-sea ice model based on a three-dimensional, frictional-geostrophic ocean, which includes isopycnal diffusion and eddy-induced advection but neglects momentum advection and acceleration. The single-layer atmosphere transports heat and moisture mostly by diffusion but includes fixed advection terms based on surface winds and an additional term to improve the interbasin moisture transport. Shortwave solar forcing for these runs was temporally constant, while outgoing planetary longwave radiation is a polynomial function of temperature and humidity, plus a greenhouse warming term proportional to the log of the ratio of carbon dioxide concentration compared to a reference preindustrial value. The sea ice height and fractional area are advected by the ocean and diffused horizontally, with thermodynamic growth and decay depending on the vertical heat flux budget. All components share the same horizontal grid, in this case $36 \times$ 36 equal-area cells, giving a latitudinal spacing increasing poleward from $3^{\circ}$ to $15^{\circ}$. In the ocean, eight logarithmically spaced depth levels were used. The seafloor topography and land surface runoff map are based on filtered observational data. The model is a prototype for the Grid Enabled Integrated Earth System Model (GENIE) project but this version has no land surface or ice sheet dynamics. There are no turbulent eddies; thus, solutions typically approach a steady state under constant forcing. The model climatology is described by Hargreaves et al. (2004) who use an ensemble Kalman filter to assimilate the observational data into the model, thereby generating an ensemble of runs with a range of values for 12 model transport parameters, all with relatively low mean errors compared to climatology. The method used to derive the ensemble presented here has been slightly extended compared to 
Hargreaves et al. (2004) in that it now takes some account of the model structural error [using the method described in Annan et al. (2005)], with the aim of producing a wide ensemble of physically reasonable members. All ensembles have 54 members. Note that only transport parameters are varied. Uncertainty in climate sensitivity is accounted for by providing results for three ensembles and climate sensitivities: 1.5, 3.0, and $4.5 \mathrm{~K}$.

\section{3) CLIMBER-2}

The CLIMBER-2.3 model (Petoukhov et al. 2000; Ganopolski et al. 2001) is a fully coupled climate model without flux adjustments. It consists of a 2.5-dimensional statistical-dynamical atmosphere module with a coarse spatial resolution of $10^{\circ}$ in latitude and $360^{\circ} / 7$ in longitude, which does not resolve synoptic variability. The vertical structures of the temperature and humidity are parameterized as well. The ocean component has three zonally averaged basins with a latitudinal resolution of $2.5^{\circ}$ and 20 unequal vertical levels. The model also includes a zonally averaged sea ice module, which predicts ice thickness and concentration and includes ice advection. In its standard carbon cycle setup, the model includes a terrestrial biosphere model (VECODE), an oceanic biogeochemistry model, and a phosphate-limited model for marine biota (Brovkin et al. 2002). In VECODE, a potential fertilization of NPP by elevated atmospheric $\mathrm{CO}_{2}$ is taken into account by a logarithmic dependence of NPP on $\mathrm{CO}_{2}$. A doubling of atmospheric $\mathrm{CO}_{2}$ leads to a $25 \%$ increase in NPP in line with outputs from explicit mechanistic models of photosynthesis in other dynamic global vegetation models (DGVM; Cramer et al. 2001). In the coupled CLIMBER-2-LPJ model, the dynamic global vegetation model LPJ replaces the terrestrial biosphere model VECODE. LPJ is used with a spatial resolution of $0.5^{\circ}$ in latitude-longitude and is called at the end of every CLIMBER-2 simulation year (Brovkin et al. 2004; Sitch et al. 2005).

\section{4) CLIMBER-3 $\alpha$}

CLIMBER-3 $\alpha$ has evolved from CLIMBER-2, resulting mainly from replacing its oceanic component with a state-of-the-art ocean model (Montoya et al. 2005). From CLIMBER-2 it includes its atmospheric component POTSDAM-2 and its atmosphere-surface interface. For coupling to version 3 of the Modular Ocean Model (MOM3), the simplified land mask of CLIMBER-2 was replaced by a realistic land mask and the resolution of the atmosphere was increased to $7.5^{\circ} \times 22.5^{\circ}$. The oceanic component of CLIMBER-3 $\alpha$ is the MOM3 OGCM, to which substantial modifica- tions, new parameterizations, and numerical schemes have been added (Hofmann and Maqueda 2006). MOM3 is a primitive equation three-dimensional OGCM with a horizontal resolution of $3.75^{\circ}$, and a $z$-coordinate vertical discretization with 24 variably spaced levels, ranging from $25 \mathrm{~m}$ in the surface to $\sim 500 \mathrm{~m}$ at depth. One main difference with respect to previous MOM versions is the fact that MOM3 includes a nonlinear, explicit free surface, which allows for the coupling of ocean and atmosphere directly via freshwater fluxes. The sea ice component is the thermodynamic-dynamic Ice and Snow Interfaces model (ISIS; Fichefet and Morales Maqueda 1997).

\section{5) LOVECLIM}

LOVECLIM is a three-dimensional earth system model that consists of five components representing the atmosphere (ECBilt), the ocean and sea ice (CLIO), the terrestrial biosphere (VECODE), the oceanic carbon cycle $(\mathrm{LOCH})$, and the Greenland and Antarctic ice sheets (AGISM) (Driesschaert 2005). ECBilt is a quasigeostrophic atmospheric model with three levels and T21 horizontal resolution (Opsteegh et al. 1998). CLIO is a primitive equation, free-surface ocean general circulation model coupled to a thermodynamicdynamic sea ice model. VECODE is a reduced-form model of the vegetation dynamics and of the terrestrial carbon cycle (Brovkin et al. 2002). It simulates the dynamics of two main terrestrial plant functional types (trees and grassland) at the same resolution as that of ECBilt. A potential fertilization of NPP by elevated atmospheric $\mathrm{CO}_{2}$ is taken into account by a logarithmic dependence of NPP on $\mathrm{CO}_{2}$. $\mathrm{LOCH}$ is a comprehensive model of the oceanic carbon cycle (Mouchet and François 1996). It takes into account both the solubility and biological pumps, and runs on the same grid as that of CLIO. Here, the ocean biology model was not used. Finally, AGISM is composed of a three-dimensional thermomechanical model of the ice sheet flow, a viscoelastic bedrock model and a mass balance model (Huybrechts 2002). The Antarctic ice sheet module also contains a model of the ice shelf dynamics. For both ice sheets, calculations are made on a $10 \mathrm{~km} \times 10 \mathrm{~km}$ grid with 31 sigma levels.

\section{6) MIT-IGSM 2.3}

The MIT-IGSM2.3 is an earth system model of intermediate complexity (Sokolov et al. 2005; Dutkiewicz et al. 2005). The atmospheric component is a zonally averaged primitive equation model (Sokolov and Stone 1998) developed from the Goddard Institute for Space Science (GISS) GCM Model II (Hansen et al. 1983). It has 11 vertical levels and $4^{\circ}$ latitudinal resolution. Each 
zonal band can consist of land, land ice, ocean, and sea ice. Surface temperature, turbulent and radiative fluxes, and their derivatives are calculated over each type of surface. The ocean model is the MITgcm (Marshall et al. 1997a,b) configured with $4^{\circ} \times 4^{\circ}$ horizontal resolution, 15 vertical layers, and realistic bathymetry. The Gent and McWilliams mixing scheme (Gent and McWilliams 1990) is implemented to parameterize the effects of mesoscale eddies. Embedded in the ocean model are a thermodynamic sea ice model (Winton 2000; Bitz and Lipscomb 1999) and an explicit carbon cycle model with a parameterization of the biological export production limited by the availability of light and nutrients (Dutkiewicz et al. 2005). The terrestrial model is composes the Community Land Model (CLM; Bonan et al. 2002) for surface heat fluxes and hydrological processes, the Terrestrial Ecosystems Model (TEM; Melillo et al. 1993); Felzer et al. 2004) for the carbon dynamics of terrestrial ecosystems, and the Natural Emissions Model (NEM; Liu 1996) for the methane and nitrogen exchange. The coupled CLMTEM-NEM model system represents the geographical distribution of land cover and plant diversity through a mosaic approach, in which all major land cover categories and plant functional types are considered over a given domain (i.e., model grid box) and are area weighted to obtain aggregate fluxes and storages. A distinguishing feature of the TEM is the explicit interaction between terrestrial carbon and nitrogen cycle.

\section{7) MoBIDiC}

MoBidiC links a zonally averaged atmosphere to a sectorial representation of the surface. The atmospheric component (Gallee et al. 1992; Crucifix et al. 2001) is based on a zonally averaged quasigeostrophic formalism with two layers in the vertical and $5^{\circ}$ resolution in latitude. The radiative transfer is computed by dividing the atmosphere into up to 15 layers. The solar radiation scheme is an improved version of the code described by Fouquart and Bonnel (1980), and the longwave radiation computations are based on the wide band formulation of the radiation equation by Morcrette (1984). The ocean component is based on the sectorially averaged form of the multilevel, primitive equation ocean model of Bryan (1969; Hovine and Fichefet 1994; Crucifix et al. 2001). The thermodynamic-dynamic sea ice component is based on the 0-layer thermodynamic model of Semtner (1976), modified by Harvey (1988, 1992), including a onedimensional meridional advection scheme. Finally, MoBidiC includes the dynamical vegetation model VECODE developed by Brovkin et al. (1997).

\section{8) UVIC ESCM 2.7}

The University of Victoria Earth System Climate Model (UVic ESCM 2.7; Weaver et al. 2001) consists of a vertically integrated, energy-moisture balance, atmospheric model, coupled to the MOM2 ocean general circulation model, a dynamic-thermodynamic sea ice model, a modified (single soil layer) version of the Met Office Surface Exchange Scheme (MOSES2) land surface model and the Topdown Representation of Interactive Foliage and Flora Including Dynamics (TRIFFID) vegetation model (Meissner et al. 2003; Matthews et al. 2004). All models use the same resolution: $1.8^{\circ} \times 3.6^{\circ}$. The ocean has 19 vertical levels. For these experiments, isopycnal (with Gent-McWilliams) mixing and flux-corrected transport were used in the ocean model. The sea ice is a simple, single-layer, thermodynamic version, with elastic-viscous-plastic dynamics. The ice sheet and ocean biology models were not used.

\section{9) HAdLEy-SCM}

To complement the computationally expensive Hadley Centre coupled climate-carbon cycle AOGCM (HadCM3LC; Cox et al. 2001), a simple model was devised that could be used to emulate the AOGCM's behavior and sensitivity to parameters (see the appendix in Jones et al. 2006a). This zero-dimensional, global mean model considers the total carbon stored in vegetation and soil, and simulates gross primary productivity (GPP), autotrophic and heterotrophic respiration, and litterfall as simple functions of global mean temperature and atmospheric $\mathrm{CO}_{2}$ concentration. GPP responds to atmospheric $\mathrm{CO}_{2}$ by a Michaelis-Menton equation defined by a maximum productivity level, and a half-saturation constant calibrated against the carbon cycle AOGCM. The impulse-response ocean uptake model is as given by Joos et al. (1996) for a 3D ocean model, but with a reduced mixed layer depth of $40 \mathrm{~m}$ to capture lower ocean uptake rates in the HadCM3LC. The ocean was also assumed to experience a lower degree of warming than the land (by a factor of 1.87) in line with the full AOGCM results (Huntingford and Cox 2000). This warming influences the uptake of carbon through the impact of the mean ocean temperature on the solubility of $\mathrm{CO}_{2}$ in seawater (Joos et al. 1996). This simple model was calibrated against the full HadCM3LC results with and without climate feedbacks on the carbon cycle, and then tested to see how well it reproduced the different behaviors associated with the stabilization scenarios. The results show it has been successful in being able to emulate the AOGCMs' behavior (Jones et al. 2006b). 
TABLE B1. Parameter values used to construct the idealized $\mathrm{CO}_{2}$ stabilization pathways. The $\mathrm{CO}_{2}$ concentrations in the last column are given for verification purposes only.

\begin{tabular}{|c|c|c|c|c|c|c|c|c|}
\hline Profile & $t_{0}(\mathrm{yr})$ & $\begin{array}{l}\mathrm{pCO}_{2}(0) \\
(\mathrm{ppm})\end{array}$ & $t_{s}(\mathrm{yr})$ & $\begin{array}{l}\mathrm{pCO}_{2}(1) \\
(\mathrm{ppm})\end{array}$ & $\begin{array}{c}(d / d t) \mathrm{pCO}_{2}(0) \\
\left(\mathrm{ppm} \mathrm{yr}^{-1}\right)\end{array}$ & $t^{\prime}(\mathrm{yr})$ & $\begin{array}{c}\mathrm{pCO}_{2, \mathrm{os}} \\
(\mathrm{ppm})\end{array}$ & $\begin{array}{c}\mathrm{pCO}_{2, t=2050} \\
(\mathrm{ppm})\end{array}$ \\
\hline SP450 & 2015.0 & 398.984 & 2100.0 & 450.000 & 2.29292 & 2017.0 & - & 445.14900 \\
\hline SP550 & 2020.0 & 410.863 & 2150.0 & 550.000 & 2.46033 & 2025.0 & - & 480.93917 \\
\hline SP650 & 2025.0 & 423.588 & 2200.0 & 650.000 & 2.62806 & 2030.0 & - & 488.62263 \\
\hline SP750 & 2030.0 & 437.112 & 2250.0 & 750.000 & 2.77642 & 2042.5 & - & 493.19541 \\
\hline SP1000 & 2042.5 & 473.140 & 2375.0 & 1000.000 & 2.91569 & 2065.0 & - & 495.10877 \\
\hline DSP450 & 2030.0 & 437.112 & 2100.0 & 450.000 & 2.77642 & 2030.1 & - & 449.70196 \\
\hline DSP550 & 2042.5 & 473.140 & 2150.0 & 550.000 & 2.91579 & 2043.0 & - & 494.29258 \\
\hline OSP350 & 2015.0 & 398.984 & 2200.0 & 350.000 & 2.29292 & 2060.0 & 445.000 & 443.14156 \\
\hline OSP450 & 2030.0 & 437.112 & 2200.0 & 450.000 & 2.77642 & 2060.0 & 486.000 & 480.28384 \\
\hline
\end{tabular}

\section{APPENDIX B}

\section{$\mathrm{CO}_{2}$ Stabilization Profiles}

The series of idealized $\mathrm{CO}_{2}$ stabilization pathways used in this EMIC intercomparison study, in the recent IPCC AR4, and previously applied in Knutti et al. (2005) are available for download online (http://www. climate.unibe.ch/emicAR4/stab.txt). The pathways of the atmospheric $\mathrm{CO}_{2}$ concentration following a dataand model-based record leading to stabilization (SP450-SP1000), delayed stabilization (DSP450 and DSP550), and overshoot stabilization (OSP350 and OSP450) were constructed following Enting et al. (1994). Enting et al. (1994) describe an approximation method using Padé approximants (fractions of polynomials) to construct various stabilization pathways given the level and rate of change of the atmospheric concentration at the beginning of the stabilization pathway and the level at which stabilization is intended. Wigley et al. (1996) adopted a "business as usual" scenario from the present times prior to the analytic scenario leading to stabilization. Here, we apply the methods described by these authors to construct nine different stabilization pathways by using recent observations of atmospheric $\mathrm{CO}_{2}$ for the industrial period until 2004, a carbon cycle model based projection of atmospheric $\mathrm{CO}_{2}$ to interconnect atmospheric observations and the analytic stabilization trajectory, and a Padé approximant following Enting et al. (1994).

Atmospheric $\mathrm{CO}_{2}$ data for the period from 1765 A.D. to 2004 A.D. are a compilation of ice core data from Siegenthaler et al. (2005) and Etheridge et al. (1996), and direct atmospheric measurements from Mauna Loa and the South Pole from Keeling and Whorf (2005) and globally averaged values from the National Oceanic and Atmospheric Administration's Climate Monitoring and Diagnostics Laboratory (NOAA/CMDL; T. Conway 2004, personal communication). From 2004 onward, model output (filtered by taking a running average with a time window of $31 \mathrm{yr}$ ) from the BernCC model's A1T run (Joos et al. 2001) was prescribed until the start of the stabilization profile at time $t_{0}(\mathrm{Ta}-$ ble B1). The compiled record was subsequently filtered by the application of a smoothing spline (Enting 1987) with a cutoff period of $200 \mathrm{yr}$ prior to 1850 A.D. and 30 yr thereafter.

Following Enting et al. (1994), the analytic expression used to interpolate between the A1T scenario and the beginning of the stabilization is defined by the expression

$$
\operatorname{pCO}_{2}(\tilde{t})=\frac{a_{3} \tilde{t}^{3}+a_{2} \tilde{t}^{2}+a_{1} \tilde{t}+a_{0}}{b_{2} \tilde{t}^{2}+b_{1} \tilde{t}+1},
$$

TABLE B2. Coefficients used with Eq. (B1) to construct the idealized $\mathrm{CO}_{2}$ stabilization pathways.

\begin{tabular}{|c|c|c|c|c|c|c|c|c|}
\hline Profile & $t_{0}$ & $t_{s}$ & $a_{0}$ & $a_{1}$ & $a_{2}$ & $a_{3}$ & $b_{1}$ & $b_{2}$ \\
\hline SP450 & 2015.0 & 2100.0 & 398.984 & 921.1826586 & 4963.6253235 & 0 & 1.8203348 & 11.1436474 \\
\hline SP450 & 2020.0 & 2150.0 & 410.863 & 442.5933040 & 1133.1029184 & 0 & 0.2987623 & 2.3131635 \\
\hline SP650 & 2025.0 & 2200.0 & 423.588 & 473.1684385 & 611.3125248 & 0 & 0.0312991 & 1.2888070 \\
\hline SP750 & 2030.0 & 2250.0 & 437.112 & 589.9078938 & 710.8691632 & 0 & -0.0478241 & 1.3650096 \\
\hline SP1000 & 2042.5 & 2375.0 & 473.140 & 893.8045101 & 601.7268872 & 0 & -0.1599155 & 1.1285869 \\
\hline DSP450 & 2030.0 & 2100.0 & 437.112 & 5911.7187374 & 95492.0505030 & 0 & 13.0798727 & 212.2331967 \\
\hline DSP550 & 2042.5 & 2150.0 & 473.140 & 1296.6314136 & 5451.7865394 & 0 & 2.0780208 & 10.0520846 \\
\hline OSP350 & 2015.0 & 2200.0 & 398.984 & 546.0670946 & -974.5234644 & 537.1212507 & 0.3054681 & 0.1449572 \\
\hline OSP450 & 2030.0 & 2200.0 & 437.112 & -307.0715051 & 8718.2450700 & 469.1856290 & -1.7822959 & 21.4877874 \\
\hline
\end{tabular}


where

$$
\tilde{t}=\frac{t-t_{0}}{t_{s}-t_{0}}
$$

The start of the stabilization pathway is at $t_{0}$, and $t_{s}$ is the point at which stabilization is reached. The coefficients are determined by specifying values for $\mathrm{pCO}_{2}(0)$, $(d / d t) \mathrm{pCO}_{2}(0)$, and $\mathrm{pCO}_{2}(1)$, as well as requiring $(d / d t)$ $\mathrm{pCO}_{2}(1)=0,\left(d^{2} /(d t)^{2}\right) \mathrm{pCO}_{2}\left(\tilde{t}^{\prime}\right)=0$ (where $\tilde{t}^{\prime}$ is the turning point at the time $\left.t^{\prime}\right)$, and $a_{3}=0$. For the two overshoot cases $\left(a_{3} \neq 0\right)$, the occurrence $\left(t^{\prime}\right)$ and value $\left(\mathrm{pCO}_{2, \mathrm{os}}\right)$ of the overshoot maximum are specified instead of defining the turning point. The parameter values used for the nine stabilization profiles are summarized in Table B1; the corresponding coefficients are summarized in Table B2. Atmospheric $\mathrm{CO}_{2}$ values for all scenarios and the year 2050, $\mathrm{pCO}_{2, t=2050}$, are additionally included in Table B1 as control values for possible recalculations of the scenarios.

\section{REFERENCES}

Annan, J. D., J. C. Hargreaves, R. Ohgaito, A. Abe-Ouchi, and S. Emori, 2005: Efficiently constraining climate sensitivity with paleoclimate simulations. Sci. Online Lett. Atmos., 1, 181-184.

Archer, D., 2005: Fate of fossil $\mathrm{CO}_{2}$ in geological time. J. Geophys. Res., 110, C09S05, doi:10.1029/2004JC002625.

_, H. Kheshgi, and E. Maier-Reimer, 1997: Multiple timescales for neutralization of fossil fuel $\mathrm{CO}_{2}$. Geophys. Res. Lett., 24, 405-408.

Bindoff, N., and Coauthors, 2007: Observations: Oceanic climate change and sea level. Climate Change 2007: The Physical Science Basis, S. Solomon et al., Eds., Cambridge University Press, 385-432.

Bitz, C. M., and W. H. Lipscomb, 1999: An energy-conserving thermodynamic model of sea ice. J. Geophys. Res., 104, $15669-15677$.

Bonan, G. B., K. W. Oleson, M. Vertenstein, S. Levis, X. B. Zeng, Y. J. Dai, R. E. Dickinson, and Z. L. Yang, 2002: The land surface climatology of the Community Land Model coupled to the NCAR Community Climate Model. J. Climate, 15, 3123-3149.

Brovkin, V., A. Ganopolski, and Y. Svirezhev, 1997: A continuous climate-vegetation classification for use in climate-biosphere studies. Ecol. Modell., 101, 251-261.

_ , J. Bendtsen, M. Claussen, A. Ganopolski, C. Kubatzki, V. Petoukhov, and A. Andreev, 2002: Carbon cycle, vegetation, and climate dynamics in the holocene: Experiments with the CLIMBER-2 model. Global Biogeochem. Cycles, 16, 1139, doi:10.1029/2001GB001662.

- S. Sitch, W. von Bloh, M. Claussen, E. Bauer, and W. Cramer, 2004: Role of land cover changes for atmospheric $\mathrm{CO}_{2}$ increase and climate change during the last 150 years. Global Change Biol., 10, 1253-1266.

Bryan, K., 1969: A numerical method for the study of the circulation of the World Ocean. J. Comput. Phys., 4, 347-376.

Caldeira, K., A. K. Jain, and M. I. Hoffert, 2003: Climate sensitivity uncertainty and the need for energy without $\mathrm{CO}_{2}$ emission. Science, 299, 2052-2054.

Claussen, M., and Coauthors, 2002: Earth system models of inter- mediate complexity: Closing the gap in the spectrum of climate system models. Climate Dyn., 18, 579-586.

Cox, P. M., R. A. Betts, C. D. Jones, S. A. Spall, and I. J. Totterdell, 2000: Will carbon-cycle feedbacks accelerate global warming in the 21st century? Nature, 408, 184-187.

,,,,---- and,- 2001 : Modelling vegetation and the carbon cycle as interactive elements of the climate system. Meteorology at the Millennium, R. Pearce, Ed., International Geophysics Series, Academic Press, 259-283.

Cramer, W., and Coauthors, 2001: Global response of terrestrial ecosystem structure and function to $\mathrm{CO}_{2}$ and climate change: Results from six global dynamic vegetation models. Global Change Biol., 7, 357-373.

Crucifix, M., M. F. Loutre, K. Lambeck, and A. Berger, 2001: Effect of isostatic rebound on modelled ice volume variations during the last 200 kyr. Earth Planet. Sci. Lett., 184, 623-633.

DeFries, R. S., R. A. Houghton, M. C. Hansen, C. B. Field, B. Skole, and J. Townshend, 2002: Carbon emissions from tropical deforestation and regrowth based on satellite observations for the 1980s and 1990s. Proc. Natl. Acad. Sci. USA, 99, 14 256-14 261.

Denman, K. L., and Coauthors, 2007: Couplings between changes in the climate system and biogeochemistry. Climate Change 2007: The Physical Science Basis, S. Solomon et al., Eds., Cambridge University Press, 499-587.

Driesschaert, E., 2005: Climate change over the next millennia using LOVECLIM, a new earth system model including the polar ice sheets. Ph.D. thesis, University Catholique de Louvain, Louvain-la-Neuve, Belgium, $214 \mathrm{pp}$.

Dutkiewicz, S., A. Sokolov, J. Scott, and P. Stone, 2005: A threedimensional ocean-seaice-carbon cycle model and its coupling to a two-dimensional atmospheric model: uses in climate change studies. Joint Program on the Science and Policy of Global Change Tech. Rep. 122, Massachusetts Institute of Technology, Cambridge, MA, 47 pp. [Available online at http:// web.mit.edu/globalchange/www/MITJPSPGC_Rpt122.pdf.]

Edmonds, J., F. Joos, N. Nakićenović, R. G. Richels, and J. L. Sarmiento, 2004: Scenarios, targets, gaps and costs. The Global Carbon Cycle: Integrating Humans, Climate and the Natural World, C. B. Field and M. R. Raupach, Eds., Island Press, 77-102.

Edwards, N., and R. Marsh, 2005: Uncertainties due to transportparameter sensitivity in an efficient 3-D ocean-climate model. Climate Dyn., 24, 415-433.

Enting, I. G., 1987: On the use of smoothing splines to filter $\mathrm{CO}_{2}$ data. J. Geophys. Res., 92, 10 977-10 984.

, T. M. L. Wigley, and M. Heimann, 1994: Future emissions and concentrations of carbon dioxide: Key ocean/atmosphere/land analyses. Division of Atmospheric Research Tech. Paper 31, CSIRO, Melbourne, Victoria, Australia, 120 pp.

Etheridge, D. M., L. P. Steele, R. L. Langenfelds, R. J. Francey, J.-M. Barnola, and V. I. Morgan, 1996: Natural and anthropogenic changes in atmospheric $\mathrm{CO}_{2}$ over the last 1000 years from air in Antarctic ice and firn. J. Geophys. Res., 101, 41154128.

Farquhar, G. D., S. von Caemmerer, and J. A. Berry, 1980: A biochemical model of photosynthetic $\mathrm{CO}_{2}$ assimilation in leaves of $\mathrm{C}_{3}$ species. Planta, 149, 78-90.

Felzer, B., D. Kicklighter, J. Melillo, C. Wang, Q. Zhuang, and R. Prinn, 2004: Effects of ozone on net primary production and carbon sequestration in the conterminous United States using a biogeochemistry model. Tellus, 56B, 230-248.

Fichefet, T., and M. A. Morales Maqueda, 1997: Sensitivity of a 
global sea ice model to the treatment of ice thermodynamic. J. Geophys. Res., 102, 12 609-12 646.

Field, C. B., and M. R. Raupach, 2004: The Global Carbon Cycle: Integrating Humans, Climate and the Natural World. Island Press, 527 pp.

Fouquart, Y., and B. Bonnel, 1980: Computations of solar heating of the earth's atmosphere: A new parameterization. Beitr. Phys. Atmos., 53, 35-62.

Friedlingstein, P., and S. Solomon, 2005: Contributions of past and present human generations to committed warming caused by carbon dioxide. Proc. Natl. Acad. Sci. USA, 102, 10 832-10 836.

_ L. Lopp, P. Ciais, J.-L. Dufresne, L. Fairhead, H. Le Treut, P. Monfray, and J. Orr, 2001: Positive feedback between future climate change and the carbon cycle. Geophys. Res. Lett., 28, 1543-1546.

— sis: Results from the $\mathrm{C}^{4} \mathrm{MIP}$ model intercomparison. J. Climate, 19, 3337-3353.

Fuglestvedt, J., and T. Berntsen, 1999: A simple model for scenario studies of changes in global climate. Center for International Climate and Environmental Research Working Paper 1999:2, CICERO, Oslo, Norway, 59 pp.

Gallee, H., J. P. Vanypersele, T. Fichefet, I. Marsiat, C. Tricot, and A. Berger, 1992: Simulation of the last glacial cycle by a coupled, sectorially averaged climate-ice sheet model. 2. Response to insolation and $\mathrm{CO}_{2}$ variations. J. Geophys. Res., 97, $15713-15740$.

Ganopolski, A., V. Petoukhov, S. Rahmstorf, V. Brovkin, M. Claussen, A. Eliseev, and C. Kubatzki, 2001: CLIMBER-2: A climate system model of intermediate complexity. Part II: Model sensitivity. Climate Dyn., 17, 735-751.

Gent, P. R., and J. C. McWilliams, 1990: Isopycnal mixing in ocean circulation models. J. Phys. Oceanogr., 20, 150-155.

Gerber, S., F. Joos, P. P. Brügger, T. F. Stocker, M. E. Mann, S. Sitch, and M. Scholze, 2003: Constraining temperature variations over the last millennium by comparing simulated and observed atmospheric $\mathrm{CO}_{2}$. Climate Dyn., 20, 281-299.

,-- , and I. C. Prentice, 2004: Sensitivity of a dynamic global vegetation model to climate and atmospheric $\mathrm{CO}_{2}$. Global Change Biol., 10, 1223-1239.

Greenblatt, J. B., and J. L. Sarmiento, 2004: Variability and climate feedback mechanisms in ocean uptake of $\mathrm{CO}_{2}$. The Global Carbon Cycle: Integrating Humans, Climate and the Natural World, C. B. Field and M. R. Raupach, Eds., Island Press, 257-275.

Gregory, J. M., and J. F. B. Mitchell, 1997: The climate response to $\mathrm{CO}_{2}$ of the Hadley Centre coupled AOGCM with and without flux adjustment. Geophys. Res. Lett., 24, 1943-1946.

_- and Coauthors, 2005: A model intercomparison of changes in the Atlantic thermohaline circulation in response to increasing atmospheric $\mathrm{CO}_{2}$ concentration. Geophys. Res. Lett., 32, 112703, doi:10.1029/2005GL023209.

Hansen, J., G. Russell, D. Rind, P. Stone, A. Lacis, S. Lebedeff, R. Ruedy, and L. Travis, 1983: Efficient three-dimensional global models for climate studies: Models I and II. Mon. Wea. Rev., 111, 609-662.

— , and Coauthors, 2007: Dangerous human-made interference with climate: A GISS modelE study. Atmos. Chem. Phys., 7, 2287-2312.

Hargreaves, J. C., and J. D. Annan, 2006: Using ensemble prediction methods to examine regional climate variation under global warming scenarios filter. Ocean Modell., 11, 174-192.

,,-- N. R. Edwards, and R. Marsh, 2004: An efficient cli- mate forecasting method using an intermediate complexity earth system model and the ensemble Kalman filter. Climate Dyn., 23, 745-760.

Harvey, L. D. D., 1986: Effect of ocean mixing on the transient climate response to a $\mathrm{CO}_{2}$ increase: Analysis of recent model results. J. Geophys. Res., 91, 2709-2718.

_ 1988: A semianalytic energy balance climate model with explicit sea ice and snow physics. J. Climate, 1, 1065-1084.

, 1992: A two-dimensional ocean model for long-term climatic simulations: Stability and coupling to atmospheric and sea ice models. J. Geophys. Res., 97, 9435-9453.

_ 2004: Declining temporal effectiveness of carbon sequestration: Implications for compliance with the United Nations Framework Convention on Climate Change. Climatic Change, 63, 259-290.

Haugan, P. M., and F. Joos, 2004: Metrics to assess the mitigation of global warming by carbon capture and storage in the ocean and in geological reservoirs. Geophys. Res. Lett., 31, 118202, doi:10.1029/2004GL020295.

Hoffert, M. I., and Coauthors, 2002: Advanced technology paths to global climate stability: Energy for a greenhouse planet. Science, 298, 981-987.

Hofmann, M., and M. A. M. Maqueda, 2006: Performance of a second-order moments advection scheme in an ocean general circulation model. J. Geophys. Res., 111, C05006, doi:10.1029/ 2005 JC003279.

Houghton, J. T., Y. Ding, D. J. Griggs, M. Noguer, P. J. van der Linden, X. Dai, K. Maskell, and C. A. Johnson, Eds., 2001: Climate Change 2001: The Scientific Basis. Cambridge University Press, $881 \mathrm{pp}$.

Houghton, R. A., 1999: The annual net flux of carbon to the atmosphere from changes in land use 1850-1990. Tellus, 51B, 298-313.

- 2003: Why are estimates of the terrestrial carbon balance so different? Global Change Biol., 9, 500-509.

Hovine, S., and T. Fichefet, 1994: A zonally averaged, three-basin ocean circulation model for climate studies. Climate Dyn., 10, 313-331.

Huntingford, C., and P. M. Cox, 2000: An analogue model to derive additional climate change scenarios from existing GCM simulations. Climate Dyn., 16, 575-586.

Huybrechts, P., 2002: Sea-level changes at the LGM from icedynamic reconstructions of the Greenland and Antarctic ice sheets during the glacial cycles. Quat. Sci. Rev., 21, 203-231.

Jansen, E., and Coauthors, 2007: Paleoclimate. Climate Change 2007: The Physical Science Basis, S. Solomon et al., Eds., Cambridge University Press, 433-497.

Jones, C. D., P. M. Cox, and C. Huntingford, 2006a: Climatecarbon cycle feedbacks under stabilization: Uncertainty and observational constraints. Tellus, 58B, doi:10.1111/j.16000889.2006.00215.x.

,-- , and $-2006 \mathrm{~b}$ : Impact of climate carbon cycle feedbacks on emission scenarios to achieve stabilization. Avoiding Dangerous Climate Change, H. J. Schellnhuber et al., Eds., Cambridge University Press, 322-332.

Joos, F., and I. C. Prentice, 2004: A paleo-perspective on changes in atmospheric $\mathrm{CO}_{2}$ and climate. The Global Carbon Cycle: Integrating Humans, Climate and the Natural World, C. B. Field and M. R. Raupach, Eds., Island Press, 165-186.

- M. Bruno, R. Fink, U. Siegenthaler, T. F. Stocker, C. Le Quéré, and J. Sarmiento, 1996: An efficient and accurate representation of complex oceanic and biospheric models of anthropogenic carbon uptake. Tellus, 48B, 397-417. 
— , G.-K. Plattner, T. F. Stocker, O. Marchal, and A. Schmittner, 1999: Global warming and marine carbon cycle feedbacks on future atmospheric $\mathrm{CO}_{2}$. Science, 284, 464-467.

—, I. C. Prentice, S. Sitch, R. Meyer, G. Hooss, G.-K. Plattner, S. Gerber, and K. Hasselmann, 2001: Global warming feedbacks on terrestrial carbon uptake under the IPCC emission scenarios. Global Biogeochem. Cycles, 15, 891-907.

Kasting, J. F., and A. Schultz, 1996: Reservoir timescales for anthropogenic $\mathrm{CO}_{2}$ in the atmosphere: Commentary. Tellus, 48B, 703-706.

Keeling, C. D., and T. P. Whorf, 2005: Atmospheric $\mathrm{CO}_{2}$ records from sites in the SIO air sampling network. Trends: A Compendium of Data on Global Change, Carbon Dioxide Information Analysis Center, Oak Ridge National Laboratory, Oak Ridge, TN

Keith, D. H., M. Ha-Duong, and J. K. Stolaroff, 2005: Climate strategy with $\mathrm{CO}_{2}$ capture from the air. Climatic Change, 74, 17-45.

Knutti, R., and T. F. Stocker, 2000: Influence of the thermohaline circulation on projected sea level rise. J. Climate, 13, 1997-2001.

— - — , and D. G. Wright, 2000: The effects of subgrid-scale parameterizations in a zonally averaged ocean model. $J$. Phys. Oceanogr., 30, 2738-2752.

—, F. Joos, S. A. Müller, G.-K. Plattner, and T. F. Stocker, 2005: Probabilistic climate change projections for $\mathrm{CO}_{2}$ stabilization profiles. Geophys. Res. Lett., 32, L20707, doi:10.1029/ 2005GL023294.

—, G. A. Meehl, M. R. Allen, and D. A. Stainforth, 2006: Constraining climate sensitivity from the seasonal cycle in surface temperature. J. Climate, 19, 4224-4233.

Lackner, K. S., 2003: A guide to $\mathrm{CO}_{2}$ sequestration. Science, $\mathbf{3 0 0}$, 1677-1678.

Lenton, T. M., M. S. Williamson, N. R. Edwards, R. Marsh, A. R. Price, A. J. Ridgwell, J. G. Shepherd, and the GENIE Team, 2006: Millennial timescale carbon cycle and climate change in an efficient earth system model. Climate Dyn., 26, 687-711.

Le Quéré, C., and Coauthors, 2003: Two decades of ocean $\mathrm{CO}_{2}$ sink and variability. Tellus, 55B, 649-656.

Liu, Y., 1996: Modeling the emissions of nitrous oxide $\left(\mathrm{N}_{2} \mathrm{O}\right)$ and methane $\left(\mathrm{CH}_{4}\right)$ from the terrestrial biosphere to the atmosphere. Ph.D. thesis, Massachusetts Institute of Technology, Cambridge, MA, 219 pp.

Manning, A. C., and R. F. Keeling, 2006: Global oceanic and land biotic carbon sinks from the Scripps atmospheric oxygen flask sampling network. Tellus, 58B, 95-116.

Marchal, O., T. F. Stocker, and F. Joos, 1998: A latitude-depth, circulation-biogeochemical ocean model for paleoclimate studies. Model development and sensitivities. Tellus, 50B, 290-316.

Marland, G., T. A. Boden, and R. J. Andres, 2006: Global, regional and national fossil fuel $\mathrm{CO}_{2}$ emissions. Trends: $A$ Compendium of Data on Global Change, Carbon Dioxide Information Analysis Center, Oak Ridge National Laboratory, U.S. Department of Energy, Oak Ridge, TN.

Marshall, J. C., A. Adcroft, C. Hill, L. Perelman, and C. Heisey, 1997a: A finite-volume, incompressible Navier-Stokes model for the studies of the ocean on parallel computers. J. Geophys. Res., 102, 5753-5766.

_ C. Hill, L. Perelman, and A. Adcroft, 1997b: Hydrostatic, quasi-hydrostatic, and nonhydrostatic ocean modeling. $J$. Geophys. Res., 102, 5733-5752.

Matear, R. J., A. C. Hirst, and B. I. McNeil, 2000: Changes in dissolved oxygen in the Southern Ocean with climate change. Geochem. Geophys. Geosyst., 1, doi:10.1029/2000GC000086.

Matthews, H. D., 2005: Decrease of emissions required to sta- bilize atmospheric $\mathrm{CO}_{2}$ due to positive carbon cycle-climate feedbacks. Geophys. Res. Lett., 32, L21707, doi:10.1029/ 2005GL023435.

, 2006: Emissions targets for $\mathrm{CO}_{2}$ stabilization as modified by carbon cycle feedbacks. Tellus, 58B, 591-602.

— A. J. Weaver, K. J. Meissner, N. P. Gillett, and M. Eby, 2004: Natural and anthropogenic climate change: Incorporating historical land cover change, vegetation dynamics and the global carbon cycle. Climate Dyn., 22, 461-479.

McGuire, A. D., J. M. Melillo, L. A. Joyce, D. W. Kicklighter, A. L. Grace, B. Moore III, and C. J. Vorosmarty, 1992: Interactions between carbon and nitrogen dynamics in estimating net primary productivity for potential vegetation in North America. Global Biogeochem. Cycles, 6, 101-124.

, and Coauthors, 2001: Carbon balance of the terrestrial biosphere in the twentieth century: Analyses of $\mathrm{CO}_{2}$, climate and land-use effects with four process-based ecosystem models. Global Biogeochem. Cycles, 15, 186-206.

Meehl, G. A., C. Covey, B. McAvaney, M. Latif, and R. J. Stouffer, 2005a: Overview of the Coupled Model Intercomparison Project. Bull. Amer. Meteor. Soc., 86, 89-93.

- W. M. Washington, W. D. Collins, J. M. Arblaster, A. X. Hu, L. E. Buja, W. G. Strand, and H. Y. Teng, 2005b: How much more global warming and sea level rise? Science, 307, 1769-1772.

—_, and Coauthors, 2007: Global climate projections. Climate Change 2007: The Physical Science Basis, S. Solomon et al., Eds., Cambridge University Press, 747-845.

Meissner, K. J., A. J. Weaver, H. D. Matthews, and P. M. Cox, 2003: The role of land-surface dynamics in glacial inception: A study with the UVic Earth System Model. Climate Dyn., 21, 515-537.

Melillo, J. M., A. D. McGuire, D. W. Kicklighter, B. Moore, C. J. Vorosmarty, and A. L. Schloss, 1993: Global climate-change and terrestrial net primary production. Nature, 363, 234-240.

Meyer, R., F. Joos, G. Esser, M. Heimann, G. Kohlmaier, W. Sauf, and U. Wittenberg, 1999: The substitution of high-resolution terrestrial biosphere and carbon sequestration in response to changing $\mathrm{CO}_{2}$ and climate. Global Biogeochem. Cycles, 13, 785-802.

Mikolajewicz, U., M. Gröger, R. Maier-Reimer, G. Schurgers, M. Vizcaíno, and A. M. E. Winguth, 2007: Long-term effects of anthropogenic $\mathrm{CO}_{2}$ emissions simulated with a complex earth system model. Climate Dyn., 28, doi:10.1007/s00382006-0204-y.

Montoya, M., A. Griesel, A. Levermann, J. Mignot, M. Hofmann, A. Ganopolski, and S. Rahmstorf, 2005: The earth system model of intermediate complexity CLIMBER-3 $\alpha$. Part 1: Description and performance for present-day conditions. Climate Dyn., 25, 237-263.

Morcrette, J.-J., 1984: Sur la paramétrisation du rayonnement dans les modèles de la circulation générale atmosphérique. Ph.D. thesis, Université des Sciences et Technologies de Lille, Lille, France, 373 pp.

Mouchet, A., and L. M. François, 1996: Sensitivity of a global oceanic carbon cycle model to the circulation and to the fate of organic matter: Preliminary results. Phys. Chem. Earth, 21, 511-516.

Nakićenović, N., and Coauthors, 2000: Special Report on Emission Scenarios. Cambridge University Press, 599 pp.

Opsteegh, J. D., R. J. Haarsma, F. M. Selten, and A. Kattenberg, 1998: ECBILT, a dynamic alternative to mixed boundary conditions in ocean models. Tellus, 50A, 348-367. 
Petoukhov, V., A. Ganopolski, V. Brovkin, M. Claussen, A. Eliseev, C. Kubatzki, and S. Rahmstorf, 2000: CLIMBER-2: A climate system model of intermediate complexity. Part I: Model description and performance for present climate. Climate Dyn., 16, 1-17.

—_, and Coauthors, 2005: EMIC Intercomparison Project (EMIP- $\mathrm{CO}_{2}$ ): Comparative analysis of EMIC simulations of current climate and equilibrium and transient responses to atmospheric $\mathrm{CO}_{2}$ doubling. Climate Dyn., 25, 363-385, doi:10.1007/s00382-005-0042-3.

Plattner, G.-K., F. Joos, T. F. Stocker, and O. Marchal, 2001: Feedback mechanisms and sensitivities of ocean carbon uptake under global warming. Tellus, 53B, 564-592.

Prather, M., and Coauthors, 2001: Atmospheric chemistry and greenhouse gases. Climate Change 2001: The Scientific Basis, J. T. Houghton et al., Eds., Cambridge University Press, 239-287.

Prentice, I. C., and Coauthors, 2001: The carbon cycle and atmospheric carbon dioxide. Climate Change 2001: The Scientific Basis, J. T. Houghton et al., Eds., Cambridge University Press, 183-237.

Randall, D., and Coauthors, 2007: Climate models and their evaluation. Climate Change 2007: The Physical Science Basis, S. Solomon et al., Eds., Cambridge University Press, 589-662.

Raper, S. C. B., J. M. Gregory, and R. J. Stouffer, 2002: The role of climate sensitivity and ocean heat uptake on AOGCM transient temperature response. J. Climate, 15, 124-130.

Sabine, C. L., and Coauthors, 2004a: Current status and past trends of the global carbon cycle. The Global Carbon Cycle: Integrating Humans, Climate and the Natural World, C. B. Field and M. R. Raupach, Eds., Island Press, 17-44.

- , and Coauthors, 2004b: The oceanic sink for anthropogenic $\mathrm{CO}_{2}$. Science, 305, 367-371.

Santer, B. D., and Coauthors, 2006: Forced and unforced ocean temperature changes in Atlantic and Pacific tropical cyclogenesis regions. Proc. Natl. Acad. Sci. USA, 103, 13 905-13 910.

Sarmiento, J. L., and C. Le Quéré, 1996: Oceanic carbon dioxide in a model of century-scale global warming. Science, 274, 1346-1350.

— T. T. C. Hughes, R. J. Stouffer, and S. Manabe, 1998: Simulated response of the ocean carbon cycle to anthropogenic climate warming. Nature, 393, 245-249.

Schimel, D., M. Grubb, F. Joos, R. Kaufmann, R. Moos, W. Ogana, R. Richels, and T. Wigley, 1997: Stabilization of Atmospheric Greenhouse Gases: Physical, Biological, and Socio-economic Implications. IPCC Technical Paper III, Intergovernmental Panel on Climate Change, Geneva, Switzerland, $48 \mathrm{pp}$.

Schmittner, A., and T. F. Stocker, 1999: The stability of the thermohaline circulation in global warming experiments. J. Climate, 12, 1117-1133.

Schneider, B., M. Latif, and A. Schmittner, 2007: Evaluation of different methods to assess model projections of the future evolution of the Atlantic meridional overturning circulation. J. Climate, 20, 2121-2132.

Semtner, A. J., 1976: A model for the thermodynamic growth of sea ice in numerical investigations of climate. J. Phys. Oceanogr., 6, 379-389.

Siegenthaler, U., and Coauthors, 2005: Supporting evidence from EPICA Dronning Maud Land ice core for atmospheric $\mathrm{CO}_{2}$ changes during the past millennium. Tellus, 57B, 51-57.

Sitch, S., and Coauthors, 2003: Evaluation of ecosystem dynamics, plant geography and terrestrial carbon cycling in the LPJ dynamic global vegetation model. Global Change Biol., 9, 161-185.

-, V. Brovkin, W. von Bloh, D. van Vuuren, B. E. N. E. Assessment, and A. Ganopolski, 2005: Impacts of future land cover changes on atmospheric $\mathrm{CO}_{2}$ and climate. Global Biogeochem. Cycles, 19, GB2013, doi:10.1029/2004GB002311.

Sokolov, A. P., and P. H. Stone, 1998: A flexible climate model for use in integrated assessments. Climate Dyn., 14, 291-303.

— , and Coauthors, 2005: The MIT Integrated Global System Model (IGSM) version 2: Model description and baseline evaluation. Joint Program on the Science and Policy of Global Change Tech. Rep. 124, Massachusetts Institute of Technology, Cambridge, MA, 40 pp. [Available online at http:// web.mit.edu/globalchange/www/MITJPSPGC_Rpt124.pdf.]

— D. W. Kicklighter, J. M. Melillo, C. A. Felzer, B. Schlosser, and T. W. Cronin, 2008: Consequences of considering carbon-nitrogen interactions on the feedbacks between climate and the terrestrial carbon cycle. J. Climate, in press.

Solomon, S., D. Qin, M. Manning, M. Marquis, K. Averyt, M. M. B. Tignor, H. L. Miller Jr., and Z. Chen, Eds., 2007: Climate Change 2007: The Physical Science Basis. Cambridge University Press, 1009 pp.

Stocker, T. F., and A. Schmittner, 1997: Influence of $\mathrm{CO}_{2}$ emission rates on the stability of the thermohaline circulation. Nature, 388, 862-865.

— and R. Knutti, 2003: Do simplified climate models have any useful skill? CLIVAR Exchanges, Vol. 8, No. 1, International CLIVAR Project Office, Southampton, United Kingdom, 7-10.

— D. G. Wright, and L. A. Mysak, 1992: A zonally averaged, coupled ocean-atmosphere model for paleoclimate studies. J. Climate, 5, 773-797.

Stouffer, R. J., and S. Manabe, 1999: Response of a coupled ocean-atmosphere model to increasing atmospheric carbon dioxide: Sensitivity to the rate of increase. J. Climate, 12, 2224-2237.

Strassmann, K. M., F. Joos, and G. Fischer, 2008: Simulating effects of land use changes on carbon fluxes: past contributions to atmospheric $\mathrm{CO}_{2}$ increases and future commitments due to losses of terrestrial sink capacity. Tellus, in press.

Tomassini, L., P. Reichert, R. Knutti, T. F. Stocker, and M. Borsuk, 2007: Robust Bayesian uncertainty analysis of climate system properties using Markov chain Monte Carlo methods. J. Climate, 20, 1239-1254.

Tsutsui, J., Y. Yoshida, D.-H. Kim, H. Kitabata, K. Nishizawa, N. Nakashiki, and K. Maruyama, 2007: Long-term climate response to stabilized and overshoot anthropogenic forcings beyond the twenty-first century. Climate Dyn., 28, doi:10.1007/s00382-006-0176-y.

Weaver, A. J., and Coauthors, 2001: The UVic Earth System Climate Model: Model description, climatology, and applications to past, present and future climates. Atmos.-Ocean, 39, 361-428.

Wigley, T. M. L., 2005: The climate change commitment. Science, 307, 1766-1769.

, and M. E. Schlesinger, 1985: Analytical solution for the effect of increasing $\mathrm{CO}_{2}$ on global mean temperature. Nature, 315, 649-652.

_ R. Richels, and J. A. Edmonds, 1996: Economic and environmental choices in the stabilization of atmospheric $\mathrm{CO}_{2}$ concentrations. Nature, 379, 240-243.

Winton, M., 2000: A reformulated three-layer sea ice model. J. Atmos. Oceanic Technol., 17, 525-531. 